\title{
LA REFORMA DE LA ORDEN DEL CARMEN EN LA PRIMERA MITAD DEL SIGLO XVI. EDUCACIÓN Y CORRIENTES ESPIRITUALES
}

\author{
Henar Pizarro Llorente \\ (Universidad Pontificia Comillas-IULCE) \\ hpizarro@,comillas.edu
}

\section{RESUMEN}

La reforma de la Orden del Carmen en el periodo pretridentino no ha merecido mucha atención por parte de los estudiosos. El proyecto auspiciado por el General Nicolás Audet impulsó el humanismo en el Carmelo y el desarrollo de un proyecto educativo. Las corrientes de espiritualidad existentes en la corte de los Reyes Católicos y de Carlos V marcaron el éxito o el fracaso de estas iniciativas, entre otras, del convento-colegio de Santa Ana en Medina del Campo.

PALABRAS CLAVE: Nicolás Audet; Baltasar Limpo; Diego Rengifo; Colegio de Santa Ana; conversos; limpieza de sangre.

\section{THE REFORM OF THE ORDER OF CARMEL IN THE FIRST HALF OF THE SIXTEEENTH CENTURY. EDUCATION AND SPIRITUAL CURRENTS}

\begin{abstract}
The reform of the Order of Carmen in the pre-Tridentine period has not received much attention. General Audet's project promoted humanism in the order and the development of an educational ideal. The currents of spirituality in the court of the Catholic Monarchs and Charles V marked the success or failure of these initiatives, among others of the convent-school of Santa Ana in Medina del Campo.
\end{abstract}

KEYWORDS: Nicolas Audet; Baltasar Limpo; Diego Rengifo; Santa Ana College; Jewish converts; limpieza de sangre.

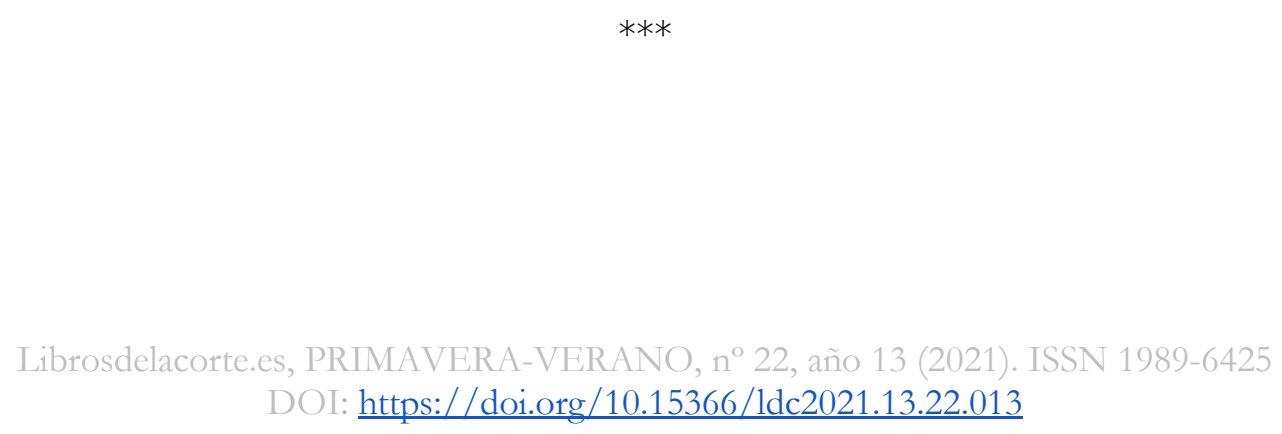


La figura de Teresa de Jesús y la incidencia de la descalcez han concitado el interés sobre la reforma de la Orden del Carmen en la segunda mitad del siglo XVI. Sin embargo, no sucede de igual manera con el proceso iniciado a finales del siglo XV y culminado por Nicolás Audet, cuyo largo generalato (1524-1562) favoreció su implantación, aunque con resultados desiguales. La visión de los historiadores de la Orden, siguiendo la estela marcada por Otger Steggink, llevó a calificar este periodo como de "aislamiento y crisis", percepción que ha sido suavizada por otros especialistas en la reforma vinculada al movimiento de la observancia como José García Oro, que prefieren usar la expresión "letargo prolongado". La necesidad de matizar estas afirmaciones fue puesta de manifiesto por la imprescindible aportación de historiadores carmelitas como Pablo María Garrido o Balbino Velasco ${ }^{2}$. Sobre la base de estos excelentes estudios, conviene aplicar nuevas perspectivas historiográficas que contribuyan a conocer mejor este periodo.

\section{EL CAMINO HACIA LA REFORMA}

El chipriota Nicolás Audet fue elegido General de la Orden del Carmen en el Capítulo General celebrado en Venecia el 15 de mayo de 1524. Su deseo de someter al Carmelo a una profunda reforma se vio respaldado por dos breves pontificios, fechados el 2 de abril de dicho año, que le confirieron amplios poderes. Desde un conocimiento apegado a la realidad, se propuso impulsar la vida comunitaria estricta y alcanzar un número significativo de conventos plenamente insertos en la observancia en cada provincia. Se evidenciaba el fracaso de la reforma procurada por los provinciales en los decenios anteriores, así como la pretensión desde la Corte de intervenir a través del Consejo Real en los escenarios de conflicto y, paralelamente, impulsar la reforma del Carmen, la Trinidad y la Merced $^{3}$.

Conocer la situación de los carmelitas en las distintas provincias tiene su mayor dificultad en la pérdida documental, especialmente en lo que se refiere a la provincia de Castilla. Sin embargo, los estudios bien cimentados en la documentación disponible no reflejan un estado tan crítico ni estático en el conjunto de las mismas a comienzos del siglo XVI. Tras la conformación de la provincia de Portugal, desgajada de Castilla en 1421 como fruto, en gran medida, de la actuación del monarca Juan I, la estructuración del territorio peninsular sufrió una nueva modificación a finales del siglo XV. Los cambios no se apreciaron únicamente en el número de las demarcaciones provinciales existentes, sino en el vigor que fueron

\footnotetext{
1 Otger Steggink, La reforma del carmelo español. La visita canónica del general Rubeo y su encuentro con Santa Teresa (1566-1567) (Ávila: Diputación Provincial de Ávila-Institución Gran Duque de Alba, 1993), 11; José García Oro, "La reforma del Carmelo castellano en la etapa pretridentina”, Carmelus 29 (1982): 130.

${ }^{2}$ Nos referimos, por ejemplo, a los trabajos de Pablo María Garrido, El hogar espiritual de Santa Teresa. En torno al estudio del Carmelo español en tiempos de la Santa (Roma: Institutum Carmelitanum, 1983); Balbino Velasco Bayón, San Juan de la Cru₹. A las raíces del hombre y del carmelita (Madrid: Editorial de Espiritualidad, 2009).

3 García Oro, "La reforma del Carmelo castellano", 144.
} 
alcanzando territorios fuera de Aragón, epicentro de la Orden hasta el comienzo de dicha centuria. A las provincias de Aragón, que asumía los territorios de Valencia y Navarra, de Cataluña y de Castilla, se unía la Bética o Andalucía, nacida de la nueva división de esta última por una bula papal fechada el 26 de febrero de 1498. Este último territorio mostró una gran actividad fundacional durante la primera mitad del siglo XVI, mientras que también tomaba mayor cuerpo la presencia carmelitana en Castilla. No deja de ser interesante para la cuestión que nos ocupa que la provincia bética se presentase como "reformada", puesto que el argumento de la reforma pudo apoyar su conformación diferenciada de Castilla y atraer el patronazgo para las fundaciones, si bien no parece que hubiera gran diferencia respecto a la situación en los conventos castellanos ${ }^{4}$.

La reorganización de las provincias carmelitanas se produjo a la par que se manifestó el deseo de los Reyes Católicos de reformar las órdenes religiosas, actuación para la que obtuvieron el respaldo papal, puesto que, el 1 de septiembre de 1499, Alejandro VI cometió la reforma de las órdenes mendicantes a Francisco Jiménez de Cisneros, al obispo de Jaén Diego Deza, y al nuncio en España y obispo de Catania Francisco Deprats ${ }^{5}$. En el contexto carmelitano, la situación de tensión entre la recién creada provincia bética y la de Castilla, que había tratado de oponerse a su nacimiento, se manifestó en la petición de amparo de su primer provincial, fray Juan de Feria, ante los Reyes Católicos, quienes, evidentemente, respaldaron las gestiones realizadas en Roma ante Alejandro VI para la consecución de su creación. Consciente de los problemas existentes, doña Isabel solicitó en 1501 una concesión del papa que diera una solución eficaz a los inconvenientes que se iban a encontrar Jiménez de Cisneros y Diego Deza. Curiosamente, el mismo fray Juan de Feria fue un destacado opositor a los impulsos reformísticos promovidos por los reyes, lo que se saldó con su sustitución en el provincialato por fray Lucas de San Vicente, quien quedó encargado de proceder a la visita de los conventos para someterlos a reforma, aunque no logró avanzar en la misma ${ }^{6}$.

Desde el gobierno de la Orden, el General Pedro Terrase, designó al también catalán Guillermo Tolzà (Tolsà, Tolzani, Tolsano, Tolça o Tolyà) como vicario general de las provincias de España, cargo que desempeñó entre 1487 y 1512, como responsable de llevar a cabo la reforma. Sin duda, su labor se vio favorecida por su

\footnotetext{
${ }^{4}$ Una de las razones expuestas para la generación de la nueva provincia fue la lejanía con los conventos de Castilla y la dificultad que ello suponía para la asistencia de los priores a los Capítulos provinciales, así como la realización de las visitas por parte de los provinciales. Balbino Velasco Bayón, Historia del Carmelo español (Roma: Institutum Carmelitarum, 1990), I, 115-136; Pablo María Garrido, El solar carmelitano de San Juan de la Cruz. La antigua provincia de Castilla (1416-1836) (Madrid: BAC, 1996), 25-26; Miguel Rodríguez Carretero, Epytome historial de los carmelitas de Andalucía y Murcia (Sevilla: Ediciones Provincia Bética, 2000), 65-73; Ismael Martínez Carretero, Los carmelitas en Sevilla. 650 años de presencia (1358-2008) (Sevilla: Ediciones Provincia Bética, 2009), 93-94.

${ }^{5}$ José García Oro, La reforma de los religiosos españoles en tiempos de los Reyes Católicos (Valladolid: Instituto Isabel La Católica de Historia Eclesiástica, 1969), 194-196; Idem, "La reforma del Carmelo castellano", 134-135.

${ }^{6}$ Garrido, El solar carmelitano, 27-28; Martínez Carretero, Los carmelitas en Sevilla, 53-54.
} 
cercanía al rey Fernando el Católico ${ }^{7}$. Provincial de Cataluña, responsabilidad que ejerció hasta 1514, fue encargado por don Fernando de realizar esta labor reformística en Aragón y Valencia en 1502, y dos años después en Castilla. En los territorios aragoneses, la labor reformadora de Tolzà se desarrolló de forma eficaz y contó con los apoyos pertinentes dentro de la propia Orden, como el de los priores Maestro Pedro Gracián, quien había provocado la intervención del rey como consecuencia de su intento de implantar la observancia en el convento de Barcelona ${ }^{8}$, y Pedro Estaña, prior del convento de Valencia, quien había sido compañero de Tolzá en Montpellier'. El desarrollo de su cometido en Castilla fue diferente, puesto que la reina Isabel había encargado la reforma a los obispos. Concretamente, en el periodo 1502-1503, Cisneros envió a sus delegados para intervenir en los conventos de la provincia. Algunas de sus medidas y métodos fueron radicales, sobre todo si, como en el caso de Toledo, se produjo resistencia al abandono de la vida "claustral" para acogerse a la observancia ${ }^{10}$. Tolzà acudió a Toledo y a otros conventos castellanos en estos difíciles y tensos momentos. Si bien no contó con el apoyo de Roma, su labor cimentó el posterior éxito de los visitadores de Audet para implementar la reforma. En este sentido, la muerte de la reina en 1504 ralentizó el empuje de la observancia, que tampoco fue auspiciada por el papa Julio II ni por el general de la Orden, el catalán Terrasse, por lo que se abrió un impás en la aplicación de las medidas reformistas desde las instancias superiores de la Orden o directamente promovidas por los reyes en el complejo escenario político tras el fallecimiento de doña Isabel. No obstante, el P. Hernando López, elegido provincial de Castilla en 1508, trató de mantener activa la dinámica. En 1510, hizo revocar las licencias concedidas a los religiosos de Castilla que prestaban servicios en las iglesias seculares, y procuró la desvinculación del P. Miguel de Madrigal del priorato perpetuo del convento San Andrés en Salamanca. Además, concedió la licencia para la que la priora del convento de la Encarnación pudiese dar un asentamiento definitivo al mismo a las afueras de Ávila con el fin de favorecer la mayor perfección religiosa de las monjas y del conjunto de la casa, que posteriormente fue el hogar espiritual de Teresa de Jesús. Del mismo modo, también fue bajo su provincialato cuando se aceptó el beatario de la Madre de Dios de Piedrahita en la obediencia de la Orden.

\footnotetext{
${ }^{7}$ Sobre el patrocinio y protección de los reyes aragoneses a la orden del Carmen desde la segunda mitad del siglo XIII, véase Balbino Velasco Bayón, "Documentos del siglo XIII sobre los carmelitas de España”, Carmelus 33 (1986): 109-123; José García Oro, "Los carmelitas castellanos y la Monarquía en el Renacimiento. Proyectos religiosos y protagonismos personales", en In labore requies (Homenaje de la Región Ibérica Carmelita a los Padres Pablo Garrido y Balbino Velasco), ed. Fernando Millán Romeral (Roma: Edizioni Carmelitane, 2007), 229-234.

${ }^{8}$ Garrido, El hogar espiritual de Santa Teresa, 86. Sobre el desprestigio que su actuación le deparó su irregular actividad, véase Velasco Bayón, Historia del Carmelo español, 158-160. Del mismo modo, Fernando el Católico intervino para apoyar la actuación del Gracián de Vilanova, provincial de Aragón (ibídem, 237-238).

${ }^{9}$ Garrido, El hogar espiritual de Santa Teresa, 85.

${ }^{10}$ Sobre los incidentes en el convento de Toledo, que además interesaba al gobierno episcopal de Cisneros, véase Velasco Bayón, Historia del Carmelo español, 165; García Oro, "La reforma del Carmelo castellano", 137; Idem, "Los carmelitas castellanos y la Monarquía", 239-242.
} 
Esta estela se prosiguió en los años posteriores, puesto que se otorgó una provisión real, el 13 de julio de 1520, para que el provincial se viese asistido por los oficiales reales para reducir a su jurisdicción a los frailes que vagaban por los caminos en respuesta a su oposición a la reforma y en el contexto de la revuelta comunera ${ }^{11}$.

En el caso de la recién creada provincia de Andalucía, el P. Pedro Chaves fue quien se ocupó en cuestiones relacionadas con la reforma. Posteriormente, fue nombrado provincial en el mismo capítulo que Audet fue elegido General en 1524. Sin embargo, la resistencia a su actuación llevó a un enfrentamiento frontal con frailes sevillanos, que le apresaron y eligieron a otro provincial, el P. Miguel de Santa María. El incidente fue tan grave que llegó a los tribunales en 1526, y a la toma de partido entre Pedro Chaves y la corte pontificia, por una parte, y Miguel de Santa María y el prior de Sevilla Pedro de Santiago, que buscaron el respaldo del Consejo Real, por otra. Esta división arrastró igualmente a los seglares e impidió que se progresase en el camino de la reforma y observancia ${ }^{12}$.

\section{LA REFORMA DE NICOLÁS AUDET Y LA FORMACIÓN DENTRO DE LA ORDEN}

Así pues, cuando los enviados de Nicolás Audet llegaron a las provincias peninsulares para implantar la reforma, se encontraron con una situación muy diferente en los distintos territorios. Los deseos del nuevo General de llevar adelante su proyecto se habían manifestado cuando ocupó el cargo de Vicario General en julio de 1523, y se plasmaron en una carta pastoral, el Isagogicom, que reflejaba el contenido de la reforma y un programa para su introducción. Cuando fue elegido General en el Capítulo de Venecia de 1524 por unanimidad, oficializó su programa junto a las Constituciones, que venían a recoger las realizadas por el beato Juan Soreth, General de la orden entre 1451 y 1471, y suponía una continuación de la estela marcada por este $^{13}$. La reforma insistía en dar impulso al ideal de la vida común, la restauración del culto divino, de las costumbres monacales y de la observancia de la Regla, así como en la reducción de las exenciones y privilegios para los estudiantes y graduados, junto con la eliminación de la venta de dispensas y beneficios, por considerar que ambas

11 Garrido, El solar carmelitano, 31-32; García Oro, "Los carmelitas castellanos y la Monarquía", 234-242.

12 Ibidem, 242-246; Steggink, La reforma del carmelo español, 28-29; Velasco, Historia del Carmelo español, 168; Martínez Carretero, Los carmelitas en Sevilla, 55-57.

13 Aurea [et] saluberrima ordinis Fratrum Deiparae virginis Mariae de mo[n]te Carmelo Statuta in Capitulo $G[e] n[e r] a l i$ Venetiis celebrato... ad instaurationem eiusdem ordinis, p[ro]pie simul \& sapienter ordinata; Isagogicon preciosissimis comparandu $[\mathrm{m}] \mathrm{ge}[\mathrm{r}]$ mis ad reformationem vitae regularis \& Sanctimoniae patrum Carmeli montis; Constitutiones ordinatae per R. Magistru[m] Io. Soret Generalem, approbatae \& publicatae per diffinitores Capituli Generalis Bruxelle[n] sis celebrati Anno D[omi]ni M.CCCC.LXVI. et correctae ac emendatae per R. Magistrum Nicolaum Audet ordinis Priorem Generalem \& diffinitores Capituli Generalis celebrati Venetiis. Anno Domini M.D.XXIIII (Venetiis: Coimpressae per Ioannem Antoniu[m] \& Fratres de Sabio...., 1524). Sobre la actuación de Soreth, véase, Giovanni Grosso, Il B. Jean Soreth (1394-1471), Priore generale, riformatore e maestro spirituale dell'Ordine Carmelitano (Roma: Textus et Studia Historica Carmelitana, 2007). 
cuestiones eran el origen esencial de los problemas ${ }^{14}$. Los provinciales españoles, a excepción de los delegados de Cataluña, no asistieron al Capítulo veneciano, puesto que el provincial de Narbona, en desacuerdo con la designación por parte de Adriano VI de Audet como Vicario General, había convocado de forma paralela un Capítulo general en Montpellier, en el que fue elegido General por los delegados de las provincias francesas y españolas ${ }^{15}$.

Tras ocupar el generalato, Audet se empleó él mismo en aplicar las directrices de la reforma, o se apoyó en miembros de la Orden de su absoluta confianza como el portugués Baltasar Limpo. Elegido inicialmente para desempeñar esta labor, la negativa del monarca luso Juan III a otorgar su permiso frustró su vinculación al proyecto. En su lugar, recibieron este encargo el provincial de Tolosa Salvatus de Quercu (Salvat Duchesne) y su socio Pedro de Vareriis. Iniciaron su andadura en España en torno al mes de abril de 1530 con la comisión de su General y los breves pontificios que respaldaban su acción. Estos poderes fueron presentados ante el Consejo Real para evitar el surgimiento de conflictos jurisdiccionales. En este sentido, Carlos V había continuado la estela de los Reyes Católicos y favoreció la aplicación de la reforma, para lo que también obtuvo los preceptivos documentos pontificios ${ }^{16}$.

Iniciaron su recorrido en Castilla, donde pudieron contar con el apoyo del catalán P. Pedro Bou, quien debía acompañarlos en el transcurso de la visita a los conventos. Celebraron Capítulo provincial, del que salió elegido nuevo provincial Alonso Muñoz, formado en Cánones, reputado como docto y enérgico, quien en 1524 había sido destinado al Studium de Padua. La reforma se aplicó a través de la visita de todos los conventos, que quedaron reducidos a la observancia, incluido el de Toledo, superándose la tensión y la oposición que había supuesto el intento del Cardenal Cisneros. Prácticamente, el principal problema en Castilla surgió en Salamanca en relación con el prior Hernando del Barco, nombrado obispo de Salona en 1521 con retención del priorato del convento de San Andrés. Su resistencia a hacer dejación de este cargo, para el que estaba proveído en perpetuidad, llevó a que él y sus partidarios se enfrentasen a los intentos del provincial Alonso Muñoz, quien trataba de cumplir las órdenes del Capítulo General celebrado en Padua en 1532 a este respecto. El conflicto se agravó y endureció, implicando al Consejo Real, y no se solucionó de manera definitiva hasta que no se alcanzó una concordia con el prelado, que obtuvo una compensación por su renuncia a dicha dignidad. Si, tras la resolución de este enfrentamiento, se había culminado el proceso con éxito en la provincia de Castilla, un número considerable de frailes abandonaron sus conventos al no soportar el rigor de la reforma. Mientras unos optaron por renunciar y pedir su

\footnotetext{
${ }^{14}$ Sorprendentemente, la figura y la reforma de Audet no han despertado un gran interés por parte de los investigadores, puesto que únicamente ha sido objeto de un estudio monográfico que ya supera los cincuenta años. Nos referimos a Adrianus Staring, Der Karmelitengeneral Nikolaus Audet und die katholische Reform des XVI. Jahrbunderts. Textus et studia histórica Carmelitana vol. 3 (Roma: Institutum Carmelitanum, 1959).

15 Smet, Los carmelitas, 243-244; Velasco, Historia del Carmelo español, 169.

16 García Oro, "Los carmelitas castellanos y la Monarquía”, 246-247.
} 
admisión en órdenes menos estrictas, otros trataron de organizar la oposición en los conventos de Requena y, como hemos señalado, en Salamanca ${ }^{17}$.

$\mathrm{Si}$ estos incidentes supusieron una excepción en la provincia de Castilla, la aplicación de la reforma en Andalucía no se desarrolló de una manera tan adecuada. A la persistencia de las divisiones vino a sumarse que el provincial Pedro Chaves fue destituido por Salvatus de Quercus a causa de su comportamiento inadecuado. Fue sustituido por un castellano observante, fray Juan de León, quien acudió como provincial de la Bética al Capítulo General de Padua de 1532. De igual modo, los cargos más relevantes de la provincia fueron ocupados por religiosos castellanos. Tras su renuncia, al quedar en Roma como consultor del general de Audet, la intervención del arzobispo de Sevilla Alonso Manrique para que se nombrase a su confesor, el Maestro Juan Quirós, alcanzó su propósito. Además, Quirós resultó elegido en el Capítulo celebrado en mayo de 1533, pero su desempeño fue breve, puesto que, en 1535, había otro provincial. La falta de continuidad en el desempeño del cargo y los mandatos breves por parte de los sucesivos provinciales no favoreció la implantación de la reforma, ni tampoco lograron acabar con los resquemores y los bandos ${ }^{18}$.

Los visitadores de Audet llegaron a Cataluña a finales de 1530. A pesar de que se trataba de un territorio en el que los superiores de los conventos habían trabajado para acoger la reforma, el efecto causado fue impactante, puesto que solamente sesenta religiosos permanecieron en ellos en toda la provincia. El resto, siendo previamente comunidades muy numerosas, decidieron abandonar los mismos por no querer someterse al rigor de la reforma en semejanza con lo sucedido en Castilla. En el Capítulo celebrado en diciembre de dicho año, se puso en manos del provincial la implantación de la observancia y la vigilancia de su cumplimiento mediante la realización de visitas canónicas. Se prohibió el contacto entre los reformados y los que no se habían querido reformar bajo pena de cárcel. La visita canónica de 1535 fue realizada por el P. Pedro Bou. La reforma del convento de Barcelona sirvió de guía para el resto, por lo que se cuidó especialmente su puesta en práctica en el mismo, que se fue orientando a través de los Capítulos provinciales ${ }^{19}$.

En el caso de la provincia de Aragón, los visitadores eligieron como provincial al P. Jaime de Casanate, que fue obispo de Alada y sufragáneo de Tarazona en julio de 1532. Para no repetir lo sucedido en Cataluña, los conventos aragoneses obtuvieron dispensas en cuanto al cumplimiento de la reforma en 1532. Muy activo durante la prelacía de Fadrique de Portugal, puesto que el arzobispo era virrey de Cataluña y no acudió a la sede episcopal, realizó por su mandato una visita pastoral a

${ }^{17}$ Ibídem, 249. La merma sufrida en el número de frailes se siguió reflejando en los decenios siguientes, como dejó constancia el testimonio de Teresa de Jesús al respecto, quien llegó a transmitir el temor por la extinción (Garrido, El solar carmelitano, 45-47; Idem, El hogar espiritual de Santa Teresa, 53).

${ }_{18}$ Martínez Carretero, Los carmelitas en Sevilla, 95-97; Garrido, El hogar espiritual de Santa Teresa, 51, 74-75, 110.

${ }^{19}$ Velasco, Historia del Carmelo español, 171-172. 
la diócesis de Zaragoza como obispo auxiliar entre 1536 y 1537. Escribió varias obras, entre las que destaca un catecismo y un comentario a la Regla ${ }^{20}$.

Tras la visita de los delegados y como medida para sustentar la implantación de la reforma, Audet nombró Vicarios generales, en primer lugar, al Maestro Juan de León, a quien posteriormente sucedieron Pedro Bou y Damián de León. Este último, que profesó en el convento de Zaragoza, pero se formó posiblemente en la Universidad de Salamanca, pudo contar con la colaboración de un joven religioso, Miguel de Carranza, quien le acompañó en sus visitas en consecución de la reforma. Se logró que, a pesar de las dificultades referidas, los Capítulos provinciales se celebraran con regularidad, por lo que se fueron generando los decretos pertinentes y necesarios en cada situación para completar el proceso. Así pues, los mejores resultados, a pesar del conflicto surgido en Salamanca, sin duda, se alcanzaron en Castilla, que fue la provincia que mejor se adaptó a la reforma. Sus seis conventos componían una provincia pequeña, pero depurada y con capacidad de producir frutos positivos. En la Brevis Instructio, compuesta a mitad de la centuria, Audet hacía constar que todos los conventos de Castilla pertenecían a la observancia. Por ello, sus miembros fueron requeridos para llevar la reforma, principalmente, a la provincia bética, donde los enviados del General encontraron graves inconvenientes para alcanzar sus objetivos ${ }^{21}$.

\section{EL INTERÉS POR LOS ESTUDIOS Y LA FUNDACIÓN DE COLEGIOS-CONVENTOS}

El movimiento de la observancia terminó por triunfar, con mayor o menor dificultad, entre los carmelitas, así como entre los franciscanos, agustinos y dominicos. Esta reforma favoreció la introducción de la vida religiosa por la vía del recogimiento, lo que cimentó la mística hispana del siglo XVI. Este modo condicionaba un marcado antiintelectualismo junto a la práctica metódica de las virtudes, el desarraigo de los vicios, la práctica sistemática de la oración mental y ascesis exigente de mortificación ${ }^{22}$. El abandono de los estudios de Teología por parte de las ramas observantes de las distintas órdenes tuvo consecuencias muy negativas para el acervo cultural y el trabajo intelectual en las mismas, que se

${ }^{20}$ Concretamente el Cathecismus Catholicus adversus agarenos y el Commentario la brevissima in Regulam B. Alberti patriarchae Hierosolimitani. Sobre su trayectoria, véase Steggink, La reforma del carmelo español, 3031; Enrique Llamas Martínez, "Carmelitas españoles pretridentinos", en Repertorio de las Ciencias Eclesiásticas en España. 3. Siglos XIII-XVI (Salamanca: Instituto de Historia de la Teología Española, 1971), 287-388; Rafael María López Melús, Carmelitas que dejaron buella (Onda [Castellón]: AMACAR, 2003), 36; José Antonio Lasarte López y Ramón Royo García, Visita pastoral de la diócesis de Zaragoza. Años 1536-1537 (Zaragoza: Institución Fernando el Católico, 2020), 9.

${ }^{21}$ Velasco, Historia del Carmelo español, 173-176.

${ }^{22}$ Melquíades Andrés Martín, "La espiritualidad española en tiempos de Carlos V", en Carlos V y la quiebra del humanismo político en Europa (1530-1558), coord. José Martínez Millán, 4 vols. (Madrid: Sociedad Estatal para los Centenarios de Felipe II y Carlos V, 2001), IV, 172-174; José Martínez Millán y Carlos Javier de Carlos Morales, dirs., Felipe II (1527-1598). La configuración de la monarquía bispana (Valladolid: Junta de Catilla y León, 1998), 21-33. 
pusieron de manifiesto desde los primeros decenios del siglo XVI. Sirva de ejemplo que, a pesar de los estímulos de Cisneros para superar la falta de interés por la formación entre los observantes franciscanos, no hubo ningún teólogo de gran significación durante la primera mitad de dicha centuria, ni los papas encontraban a ningún religioso preparado a quien encargar labores de gobierno ${ }^{23}$. En cuanto a los agustinos observantes, la situación no era mucho mejor. Cuando se publicó la convocatoria del Concilio de Trento en 1544, los conventos castellanos no pudieron ofrecer al General ningún teólogo adecuado para acudir a la reunión. El General de la orden tomó medidas urgentes para paliar esta situación de esterilidad, escogiendo a una serie de religiosos para que se formasen en la Universidad de París y en otras italianas ${ }^{24}$. En el caso de los dominicos, fue fundamental la actuación de García de Loaysa, Maestro General de la Orden. Supo atraer a fray Juan Hurtado de Mendoza y su grupo de reformadores para sustentar la unidad dentro de esta y evitar el surgimiento de distintas ramas. Se enfatizó el apego a una vida profundamente ascética y se reforzó la actuación para favorecer la moralización de la sociedad y la defensa de la justicia a través de la predicación. El predicador había de convertirse en ejemplo de austeridad y de vida para los fieles, y, en consecuencia, formase debidamente para cumplir con este cometido ${ }^{25}$.

De igual manera, la renovación espiritual que se vivió a principios del siglo XVI fue acompañada de una renovación educativa que se estaba gestando a la vez y estrechamente vinculada a la misma. En la Corte de los Reyes Católicos, las facciones cortesanas se identificaron y apoyaron distintos proyectos educativos que se identificaron con distintas vías en el ámbito de la espiritualidad. Si bien, en realidad, estas cuestiones fueron complejas y diversas, puesto que ni las órdenes religiosas ni las corrientes de espiritualidad fueron homogéneas ni uniformes en un escenario tan cambiante, vamos a seguir un esquema que, como tal, supone una simplificación, pero que nos puede orientar respecto al proyecto educativo que promovió la reforma carmelitana. Es conocido que la reina Isabel se mostró cercana a la reforma franciscana, cuya espiritualidad, tendente a la mística, conocía y apreciaba por ser tradicionalmente franciscanos los confesores de los miembros de la familia real ${ }^{26}$. Los colectivos reformados y observantes se mantuvieron a su lado en momentos de debilidad política, lo que la reina premió concediéndoles un marcado protagonismo en el ámbito cortesano. Los "fernandinos" sintonizaron con la reforma de la Orden de Santo Domingo, que insistía en los aspectos intelectuales en consonancia con los

${ }^{23}$ Melquíades Andrés Martín, "Reforma y estudios de Teología en los franciscanos españoles", Anthologica Annua 8 (1961): 43-84.

24 Ângel Martínez Cuesta, "El movimiento recoleto en los siglos XVI y XVII", Recollectio 5 (1982): 5-47; ampliado en el libro Agustinos Recoletos. Historia y espiritualidad (Madrid: AGVSTINVS, 2007), 51103.

25 Vicente Beltrán de Heredia, Las corrientes de espiritualidad entre los dominicos de Castilla durante la primera mitad del siglo XVI (Salamanca: Biblioteca de Teólogos Españoles, 1941), 17-26.

26 Anastasio López OFM, "Confesores de la familia real de Castilla", Archivo Iberoamericano 31 (1929): 5-75; Juan Meseguer Fernández, "Franciscanismo de Isabel la Católica", Archivo Iberoamericano 19 (1959): 153-195. 
principios tradicionales de la Orden. Las discrepancias con los teólogos y practicantes de la observancia franciscana se concretaban en cuestiones diversas como la lectura de los libros espirituales en lengua romance, la frecuencia excesiva del sacramento de la comunión, o la práctica habitual de la oración mental. Algunos teólogos dominicos miraban con recelo estas actividades por considerar que podrían derivar en herejía. Se entendía que era más conveniente atenerse de forma exclusiva a la razón fundada en las Sagradas Escrituras y en las resoluciones de la Iglesia sin pretender introducir ninguna innovación. Evidentemente, las corrientes más místicas admitían la autoridad de la Iglesia, pero creían que las personas espirituales recibían inspiraciones de Dios. En consecuencia, se promovía la renovación cristiana por medio de la oración y la frecuencia de los sacramentos. Su exigencia en el cumplimiento espiritual y su actitud crítica con la Iglesia también conectaba, aunque no se identificaron plenamente, con la vía humanista de Erasmo. Por ello, no resulta extraño que el Cardenal Cisneros la asumiera y difundiera en la Universidad de Alcalá de Henares, mientras que el Colegio de Santo Tomás, fundado por el dominico Diego Deza en Sevilla, representaba una propuesta diferente con la prohibición expresa del estudio de los maestros nominalistas ${ }^{27}$.

La reforma proyectada por Audet en el Carmelo, más tardía y madura, vinculaba el rigor de la observancia, que se vio reforzado en los Capítulos Generales de 1532, 1539 y 1548, con el favorecimiento y modernización de la educación dentro de la Orden. Los estudios se vieron promovidos y se entendieron como el sustento y proyección futura de la propia reforma, que, como hemos referido, favorecía el gobierno centralizado de la Orden y la abolición de cualquier propiedad para alcanzar el horizonte de la estricta vida común. Quedó establecido que hubiese un colegio para los estudios de Gramática en cada provincia, y se proyectaba contar con un Estudio General, donde cada convento había de mandar a un estudiante y ocuparse del mantenimiento económico del mismo durante su estancia en el centro. Si no aprovechaba suficientemente esta oportunidad, debía ser expulsado sin demora y sustituido por otro candidato ${ }^{28}$. En cuanto a los Estudios Generales, su implantación se había iniciado en los decenios centrales del siglo XIV. Los profesores podían ser maestros, si habían obtenido este grado en la Universidad, bachilleres, dedicados a la enseñanza de las Sentencias, y bíblicos, que explicaban las Sagradas Escrituras. No estaba definida la duración de los estudios, que se estructuraban en tres categorías: Gramática, Filosofía y Teología. Además, el centro solía contar con una importante biblioteca. Mientras que se siguió avanzando en la formación de los novicios, en los primeros años del siglo XVI se optó por recurrir a maestros seglares, práctica común en los Estudios Generales, que habían de enseñar a los hermanos y también a niños.

\footnotetext{
${ }^{27}$ En torno a estas cuestiones, véase Andrés Martín, "La espiritualidad española”, 163-166; Idem, "Corrientes culturales en tiempos de los Reyes Católicos y recepción de Erasmo", en El erasmismo en España, eds. Manuel Revuelta Sañudo y Ciriaco Morón Arroyo (Santander: Sociedad Menéndez Pelayo, 1986), 73-95; Vicente Muñoz Delgado, “Nominalismo, lógica y humanismo”, ibídem, 109-174; Joseph Pérez, "El erasmismo y las corrientes espirituales afines", ibídem, 323-338.

${ }_{28}$ Manuel MariaWermers, "Os primeiros estatutos do colegio universitário carmelita de Coimbra", Carmelus 9 (1962): 98.
} 
El propósito perseguido se materializaba a mitad de la centuria. Con las medidas adoptadas en los Capítulos provinciales, se promovió que se tratase de buscar jóvenes que instruir para que ingresasen en la Orden, que se encontraba muy mermada de religiosos, y, tras su paso por el Estudio General, pudiesen ser enviados a la Universidad los más idóneos ${ }^{29}$.

Evidentemente, los carmelitas vinculados a la implantación de la reforma de la observancia durante el reinado de los Reyes Católicos se habían formado en dichos centros. En el caso de Cataluña, los Estudios Generales de Perpiñán, Barcelona y Lérida solían enviar a sus estudiantes aventajados a la Universidad de París ${ }^{30}$. En el caso del vicario general Guillermo Tolzà, tras pasar por los Estudios Generales de Montpellier y Perpiñán, estudió en dicha Universidad Cánones, Leyes y Teología, y también fue profesor en la misma. Después, fue regente del Estudio General de Perpiñán, donde también ocupó la cátedra de Teología y adquirió fama como predicador $^{31}$. La preocupación por la enseñanza quedó reflejada en la reiteración en el tratamiento de este tema en los Capítulos provinciales, y, en el celebrado en 1522 se estableció el principio "cum ignorantia sit magistra errores", por lo que se reiteró el envío de estudiantes a la Universidad de París ${ }^{32}$. El convento de Barcelona, vanguardia de la reforma en Cataluña, albergó el Estudio General, al que estuvo vinculado el P. Bartolomé Garau, cuya actividad favoreció la implantación de la reforma promovida por Audet. En el Capítulo celebrado en este cenobio en 1535, al que asistió Pedro Bou, se puso de manifiesto que el principal inconveniente para la promoción de los estudios era la falta de capacidad económica ${ }^{33}$. Así mismo, en referencia a la educación en la provincia de Cataluña, también destacaba el convento de Lérida. Llegaron al centro estudiantes provenientes de las provincias de Aragón y de Castilla, como Miguel de Madrigal, a quien encontraremos vinculado a la promoción de los estudios en su provincia con posterioridad.

No obstante, uno de los principales centros de formación de la Península se encontraba en la provincia de Aragón. Nos referimos a los Estudios Generales de Valencia, fundados en 1378. En su relación con la universidad de Valencia, destacaba, a finales del siglo XV, Pedro Estaña. Tras ser lector en el convento de Montpellier, aparece en los primeros años del siglo XVI como maestro en el convento de Valencia. Fue favorecido por el general de la Orden, Pedro Terrasse y nombrado prior del convento y catedrático de Prima en Teología en 1509 en la Universidad de Valencia. Su apoyo a la reforma propició que fuese provincial y visitador en

${ }^{29}$ Velasco, Historia del Carmelo español, 180 ss. Ciertamente, el fortalecimiento de la formación de los novicios fue iniciada en tiempos del General Soreth, de cuya reforma, como hemos referido, fue continuador Audet adaptando los aspectos necesarios a las nuevas circunstancias. En torno a estas cuestiones, véase Giovanni Grosso, "Tra fedeltà e reforma. Cultura e libri nei conventi dei Carmelitani del XVI secolo", en Libri e biblioteche: le letture dei frati mendicanti tra Rinascimento ed età moderna (Spoleto: Centro Italiano di Studi sull'Alto Medioevo, 2019), 228-229.

${ }^{30}$ Garrido, El hogar espiritual de Santa Teresa, 29-31.

${ }^{31}$ Sobre la figura de Tolzá, véase la voz recogida en Balbino Velasco Bayón, Diccionario biográfico del Carmelo ibérico (Roma: Edizioni Carmelitane, 2019).

32 Velasco, Historia del Carmelo español, 192-194, 208.

${ }^{33}$ Garrido, El hogar espiritual de Santa Teresa, 34. 
Portugal $^{34}$. Así mismo, el Estudio General de Huesca, fundado por Pedro IV de Aragón, con el establecimiento de Facultades de Teología, Derecho canónico, Derecho civil, Medicina y Filosofía y Artes, tuvo una especial significación, si bien se extinguió a mediados del siglo XV. Logró remontar a mediados del siglo XVI, cuando destacaron una serie de carmelitas vinculados a la Universidad de Huesca. Los catedráticos Jaime Jordán, Pedro José Santapau y Guillém Lastao, entre otros, enseñaron Filosofía y Teología en la Universidad, así como en diversos conventos. Tanto los estudiantes de los cenobios valencianos como aragoneses, destacadamente Zaragoza y Calatayud, enviaron a sus estudiantes a formarse tanto a la Universidad de París como a Salamanca, y ocasionalmente al Estudio de Padua ${ }^{35}$.

Así pues, las provincias de Cataluña y Aragón presentaban un panorama activo en el ámbito cultural, inercia de su herencia medieval, y perfectamente integrado y relacionado con centros universitarios franceses e italianos. Ciertamente, la perdida de documentación impide reconstruir la vida cultural de los conventos de la provincia de Castilla durante el siglo XV, pero esta no debió de ser destacada, puesto que sus cenobios se fundaron en lugares de escasa relevancia social y política con la excepción de Toledo, por lo que se mantuvo en un segundo plano. El convento toledano fue centro de estudios de Arte y Teología desde mediados del siglo XV. Sin embargo, esta trayectoria se frustró y la situación se agravó con la expulsión realizada por Cisneros de los frailes del convento de Toledo al hilo de su resistencia a adoptar la observancia, y del desposeimiento del edificio y de sus enseres, que fueron entregados a las comendadoras de la Orden de Santiago con el beneplácito de la reina Isabel ${ }^{36}$.

Por otra parte, la situación de pobreza existente en la mayoría de los conventos imposibilitaba el acceso de los religiosos a la Universidad por no poder asumir los conventos el coste del pago de los estudios. Del mismo modo, la paupérrima situación económica también tuvo su reflejo en las limitaciones para enviar a la imprenta manuscritos y dar difusión a la producción intelectual de los carmelitas castellanos. No obstante, dentro de los márgenes permitidos por esta penuria, el número de graduados en centros universitarios, principalmente en Salamanca, no fue desdeñable ${ }^{37}$. En esta ciudad se encontraba el convento-colegio de San Andrés, que funcionaba como casa de estudios desde, al menos, los últimos decenios del siglo XV, y que aparece agregado a la Universidad salmantina, lo que le convirtió en el centro de formación más importante para los estudiantes castellanos y para los alumnos carmelitas de la Universidad. En dicho colegio de San Andrés estudió Baltasar Limpo, inserto en la práctica habitual de intercambio entre

34 Ibídem, 43-44; Velasco, Historia del Carmelo español, 198-199; López Melús, Carmelitas que dejaron buella, 35. Junto a Estaña, también fue catedrático de Prima en la Universidad de Valencia y en Avignon el maestro Diego de Atienza.

35 Balbino Velasco Bayón "El convento de Carmelitas de Huesca", Carmelus 26 (1979): 142.

${ }^{36}$ Idem, "El convento de carmelitas calzados de Toledo", Anales toledanos 17 (1983): 31.

${ }^{37}$ Garrido, El solar carmelitano, 35-38. 
estudiantes portugueses y castellanos ${ }^{38}$. Vinculados a la universidad igualmente estuvieron los referidos Miguel de Madrigal y Hernando del Barco, quien trató de promover la educación en la provincia de Castilla a través de la fundación de un colegio en Valladolid. La vinculación de San Andrés a la Universidad hizo que se inscribiese en el movimiento de renovación de la escolástica propiciado por Francisco de Vitoria, con el que se identificaba también el prior Hernando del Barco. Quizás por ello no se desarrolló una línea específicamente carmelitana ${ }^{39}$.

La provincia bética no tuvo centros de formación propios hasta mediados del siglo XVI, por lo que envió a sus estudiantes al Colegio de Santo Tomás de Sevilla, fundado por Diego Deza. No obstante, la peculiaridad de la provincia andaluza fue que destinó muchos más estudiantes a la Universidad de Alcalá de Henares que el resto de los territorios peninsulares, lo que se puso de manifiesto en la continuidad de la tradición escriturística y de estudios bíblicos iniciada en el siglo XV en algunos conventos y en el influjo del erasmismo ${ }^{40}$.

La reforma promovida por Nicolás Audet en el Carmelo contó con un proyecto educativo concebido para que diese fruto en las generaciones venideras dentro de la Orden con su adecuación a la observancia. Ciertamente, el General favoreció su aplicación en las provincias más occidentales, puesto que, en los territorios italianos, sustentó la expansión de la Congregación Mantuana por promover un proyecto con fuerte raigambre humanística ${ }^{41}$. La Congregación Mantuana había iniciado su andadura en 1413, cuando el prior Jacobo de Alberto activó la reforma de su convento. Su intención era retornar al viejo espíritu de la Regla y a la antigua forma de vida carmelitana, que se entendía desvirtuada. Según han establecido diversos estudios, la Congregación Mantuana impuso una forma de vida que tuvo muchos puntos en común con la posterior reforma teresiana, incrustada, por tanto, en la experiencia atesorada en el Carmelo. Otra congregación de reformados en el seno de la Orden fue la de Albí, que creció a la sombra de la mantuana por obra del Obispo Luis Ambois. Ambas congregaciones favorecieron la espiritualidad y la observancia carmelitana, pero, debido al peligro que su existencia suponía para la unidad de la Orden, desaparecieron mediante los decretos papales de Pío VI y Gregorio XIII respectivamente ${ }^{42}$.

Para llevar adelante el impulso educativo, Audet siguió manteniendo su inclinación por el portugués Baltasar Limpo. Enviado desde el convento de Lisboa para realizar sus estudios de Teología en la Universidad de Salamanca, Limpo ocupó

\footnotetext{
38 Así, por ejemplo, junto a Limpo, destaca el ejemplo de Sebastián de Farías, que llegó procedente de Castilla para estudiar tres años de Filosofía en el convento de Lisboa. Garrido, El hogar espiritual de Santa Teresa, 49; Balbino Velasco Bayón, El Colegio Mayor Universitario de carmelitas de Salamanca (Madrid: CSIC, 1978), 19.

${ }^{39}$ Garrido, El solar carmelitano, 41-42; Idem, El hogar espiritual de Santa Teresa, 66-67.

40 Ibídem, 58-61; Francisco Álvarez, "El movimiento bíblico en Sevilla durante el siglo XVI", Archivo Hispalense 26 (1957): 13.

${ }^{41}$ Wermers, "Os primeiros estatutos do colegio universitário", 96.

42 Smet, Los carmelitas, 117-121; Grosso, "Tra fedeltà e reforma. Cultura e libri", 229-236; Fortunato Antolín, OCD, "Notas sobre el padre Rubeo y la congregación mantuana", Revista Monte Carmelo 101/1 (1993): 69-83.
} 
la cátedra de prima en la Universidad de Lisboa en 1521. Sus excelentes dotes para la predicación facilitaron su nombramiento como predicador real en la capilla de Juan III y como confesor de la reina Catalina, hermana menor de Carlos V, y de los infantes, lo que le proporcionó gran notoriedad en la Corte lusa. Así mismo, fue provincial entre 1523 y 1526, año en que fue nombrado prior del convento lisboeta de Santa María. Designado a propuesta del monarca como visitador y reformador de los carmelitas portugueses en 1529 por un periodo de seis años, contó con amplios poderes para poder cumplir con este cometido. Al finalizar este plazo, volvió a hacerse cargo del provincialato entre 1533 y 1537. Inserto en el proyecto de Audet, fue durante los meses que mediaron entre su desempeño del provincialato y su ocupación de la mitra de Oporto cuando dio forma a la fundación del Colegio del Carmen en Coimbra, que culminó inmerso en las labores de su prelacía. Si bien se concibió como un centro para que se formasen en Filosofía y Teología los clérigos de su diócesis, cuya construcción se inició en 1540, finalmente fue destinado a la formación de los carmelitas, que ocuparon el recinto a finales de 1543. El proyecto educativo contó con el patrocinio de Juan III, quien también sufragó los gastos de los religiosos que estudiasen en la Universidad ${ }^{43}$. El encuentro personal entre Audet y Limpo durante la celebración de la primera etapa del Concilio de Trento terminó por perfilar la fundación, que el prelado donó a la Orden del Carmen en enero de 1547. Si bien ya se había iniciado el trabajo de establecer unos estatutos, no se finalizaron hasta $1555^{44}$. En los mismos, quedaba perfectamente reflejado el programa reformista de Audet, puesto que se establecía que se habían de regir por las disposiciones dictadas por la reforma de la Orden. Se establecía que los quince colegiales previstos habían de ser profesos carmelitas, de entre dieciséis y veinticinco años, limpios de sangre en cuarto grado, sin que se hubiesen visto relacionados con el mantenimiento de ideas nuevas, erróneas o heréticas, y escogidos entre los mejores estudiantes de los conventos portugueses. También habría cuatro hermanos legos y dos empleados. Se establecía una planificación de los estudios en ocho años: tres dedicados al estudio de la Filosofía y cinco al de la Teología. El último año en el centro seguirían un curso de Cánones, así como de materias provechosas para la conciencia. La asistencia a las clases se realizaba en el propio colegio y también en la universidad. Con un régimen disciplinario severo, el centro se ponía bajo la dirección de un rector, un vicerrector y un maestro regente. El Capítulo provincial era el encargado de designar al rector por un período de tres años, reelegible para otro trienio. Dicho capítulo también se encargaba de elegir al maestro regente, cuya labor era presidir las conclusiones, así como las obligaciones definidas por los estatutos y constituciones de la Orden. El cargo de vicerrector recaía en un colegial que se estimase idóneo y equivalía al de subprior de los conventos. La oración y el estudio

${ }^{43}$ Balbino Velasco Bayón, História da Ordem do Carmo em Portugal (Lisboa: Paulinas, 2001), 94-95; Idem, El colegio Mayor universitario, 24- 25; Wermers, "Os primeiros estatutos", 105.

44 Ibídem, 107 ss; Velasco, História da Ordem do Carmo, 95-98. 
ocupaban la jornada con un horario establecido con ligeras variaciones entre el invierno y el verano ${ }^{45}$.

El proyecto de generar un centro educativo en Castilla que respondiese al impulso de la reforma de Audet partió de premisas muy distintas, puesto que contó con un exiguo patrocinio regio y se desvinculó de los provinciales de la Orden, haciendo que dependiese directamente del General. En este sentido, los provinciales castellanos habían seguido la estela de Alonso Muñoz en lo que se refiere a la reforma. El colegio de San Andrés fue declarado Estudio General de la Orden en el Capítulo General de 1532, pero no para que albergase estudios y profesores propios, sino como centro interprovincial. Su propósito de hacer observar la Regla condicionó la obligatoriedad de que todos los estudiantes carmelitas de la universidad salmantina residiesen en el mismo ${ }^{46}$. Así pues, desde 1532, el colegio salmantino de San Andrés recibía estudiantes procedentes de todas las provincias españolas, así como el tradicional aporte de estudiantes lusos, para que pudiesen cursar sus estudios en la Universidad de Salamanca. La declaración oficial para actuar como colegio común de todas las provincias llegó en el Capítulo General de Venecia de 1548, así como un conjunto de normas para favorecer su buen funcionamiento. Esta confirmación oficial de una dinámica existente vino a sustentar la formación de unos estudiantes que supusieron el sustrato intelectual de la Orden en el escenario postridentino ${ }^{47}$.

El crecimiento de San Andrés llevó a que se valorase las opciones de ampliación. Sin embargo, en 1549, el P. Diego Rengifo, rector perpetuo del mismo, obtuvo el permiso pontificio a través del breve despachado por Paulo III para desarrollar el proyecto de fundación de un colegio-convento en Medina del Campo, dada la carencia de centros educativos en la zona y el naufragio del proyecto de fundación del convento de Valladolid impulsado por Hernando de Barco. El provincial Gregorio Fernández secundó el propósito de Rengifo, lo que conllevó que no se procediese a la ampliación del colegio de San Andrés en Salamanca. Además de establecer una serie de disposiciones respecto al número de estudiantes y a las cuestiones económicas vinculadas a su construcción, se autorizaba a Rengifo, nombrado administrador perpetuo, a redactar los estatutos para el gobierno del centro y a irlos modificando para adecuarlos convenientemente a las circunstancias sin que para ello tuviese que contar con licencia de ningún superior. Así pues, el proyecto del colegio de Santa Ana en Medina del Campo se puso en marcha en paralelo al desarrollado por Limpo en Coimbra, por lo que el proyecto educativo de Audet también tuvo su reflejo en Castilla, aunque con muchos menos apoyos.

\footnotetext{
45 "4-6 horas: levantarse e estudo. 6-8 horas: Orações, Missa. 8 horas: irão às aulas. 11 horas: jantar. Em seguida: repetição das lições. 15 horas: Vesperas-aulas-estudo. 19 horas: ceia. 20-21 horas: repetição das lições. 21-22 horas: Matinas. 22-4horas: repouso nocturno" (Wermers, "Os primeiros estatutos", 117).

${ }^{46} \mathrm{El}$ proceso no estuvo exento de resistencias, destacando el caso del estudiante portugués Pedro Fogaça (Garrido, El solar carmelitano, 53; Velasco, El Colegio Mayor Universitario, 19-20).

${ }^{47}$ Sobre la carencia de fuentes para conocer los estatutos del centro, véase Garrido, El solar carmelitano, 54-55.
} 
Evidentemente, la actuación contó con el respaldo de Damián de León, provincial de Aragón y Valencia, y Vicario General para Castilla y Andalucía, que ratificó todas las atribuciones excepcionales concedidas por el papa ${ }^{48}$. El 26 de mayo de 1552, otorgó plenos poderes al P. Rengifo para fundar un colegio-convento en la citada localidad, con la autorización para nombrar profesores de cualquiera de las provincias de España que quisieran vincularse al proyecto sin que tuviese que mediar el permiso del provincial. Aún más significativo fue que se eximía también de la jurisdicción del provincial de Castilla, quedando bajo la autoridad directa del General de la orden. Así pues, el convento y colegio de Medina nacían apegados a la observancia y al proceso renovador de Audet, y en el mismo se forjó el vínculo de Juan de Yepes (Juan de la Cruz) con el Carmelo. Sin duda, las facultades otorgadas a Rengifo fueron extraordinarias también por los medios puestos a su disposición por el papado, puesto que fue autorizado a aplicar a la construcción del colegio los fondos obtenidos por la predicación de la bula de Nuestra Señora del Carmen, por lo que hubo de establecer una capitulación con los tesoreros generales de la Cruzada, que fue ratificada por el comisario General de Cruzada, que interesó a los años 1552 y 1553. El apoyo del prior general de la Orden al P. Diego Rengifo se reflejó en el nombramiento como procurador de las cuatro provincias carmelitas españolas ante la curia real en $1555^{49}$.

La fundación del colegio se realizó en 1556, ubicado en unas casas que el consejero de Hacienda Rodrigo de Dueñas donó colindantes con la ermita de Santa Ana. Carlos V otorgó la pertinente licencia y contribuyó con la aportación de algunos terrenos, que vinieron a sumarse a la larga lista de bienes donados al colegio por el propio Rengifo $^{50}$. Las disposiciones iniciales, fijadas en 1560, establecieron que en el mismo habría un lector de gramática y otro de artes, este último preferentemente religioso carmelita, que se debía ocupar de enseñar no solo a los frailes sino también a todos los alumnos de la zona que deseasen recibir las lecciones. A la espera de comprobar la viabilidad económica del proyecto, Rengifo planificaba los estudios de Teología para frailes ordenados de misa, que acudiesen a Salamanca o a otras universidades a oír las lecciones, pero que viviesen en recogimiento según quedase establecido en los estatutos que se diesen al colegio. El propio Rengifo se reservaba para sí la facultad de fijar los mismos para el buen gobierno del centro, así como el nombramiento de los visitadores que velasen por la recta administración de los bienes, que estarían bajo la responsabilidad del Rector del colegio ${ }^{51}$.

${ }^{48}$ En torno a la trayectoria de Damián de León, véase López Melús, Carmelitas que dejaron buella, 37; Velasco, Diccionario biográfico del Carmelo ibérico.

${ }^{49}$ Las excepcionales condiciones concedidas a Rengifo pueden encontrarse de manera más detallada en Balbino Velasco Bayón, San Juan de la Cruz. A las raíces del hombre y del carmelita (Madrid: Editorial de Espiritualidad, 2009), 153-156.

${ }^{50}$ Sobre las habilidades para el comercio y las cuestiones económicas, así como su inserción en los círculos de mercaderes de Medina del Campo, véanse las noticias que aporta el P. Velasco en ibídem, 157-160. Sobre Rodrigo de Dueñas, véase Carlos Javier de Carlos Morales: http://dbe.rah.es/biografi as/16682/rodrigo-de-duenas (consultado 14 de diciembre de 2020).

51 Velasco, San Juan de la Cruz, 160-162. 
Rengifo siguió sustentando su proyecto en el apoyo otorgado por la autoridad pontificia a través del nuncio Alejandro Crybellus, que comisionó en 1562 al prior de San Bartolomé de Medina y al abad de la colegial de Valladolid para que velasen por el cumplimiento del breve papal de 1549. La razón de esta insistencia podría estar vinculada al fallecimiento de Nicolás Audet, puesto que el colegio dependía en exclusiva de la autoridad del prior general. Al año siguiente, en 1563, se aumentaron y concretaron las disposiciones iniciales. Se establecía que el colegio había de albergar ocho frailes colegiales y cuatro familiares, elegidos por los priores de los ocho conventos más próximos a Medina del Campo, y la estancia en el colegio no podía superar los ocho años. Se constituían dos cátedras de Teología y dos de artes, cuyos ocupantes, elegidos a través de una oposición semejante a existente en las Universidades de Salamanca y Valladolid, habían de leer una lección al día en las cátedras de Teología y dos en las de Artes. Se señalaba que se debía seguir a Santo Tomás en Teología y a Domingo Soto en Filosofía ${ }^{52}$. De igual modo, se dispuso que las normas de gobierno se inspirasen en las que regían en el colegio de San Gregorio de Valladolid, perteneciente a la orden de Santo Domingo y ajustados a su regla, pero con una marcada tendencia a favorecer el estudio y la piedad, mientras que los regidores de dicha población quedaron como conservadores y patronos del colegio. Rengifo no vivió para ver los resultados de estas gestiones, puesto que falleció el mismo año de 1563. El mayor impedimento para el normal funcionamiento del colegio fue la falta de cumplimiento de los acuerdos alcanzados por parte de los regidores medinenses. De nada sirvieron los llamamientos realizados por uno de los catedráticos de teología, el P. Martín García, en el Capítulo general reunido en Piacenza en 1575 para que se hiciese cumplir a los regidores con el acuerdo, puesto que, si no se procedía de esta manera, y en consecuencia con lo establecido por Rengifo, los bienes legados para Santa Ana pasarían al convento de San Andrés. Esta fue la determinación adoptada por el general Rubeo, lo que ponía fin a la generación de un nuevo centro de estudios en Castilla ${ }^{53}$.

\section{LA PRESENCIA DE LA ESPIRITUALIDAD CARMELITANA EN LA CORTE}

La reforma de las órdenes religiosas formó parte de la estrategia política de los Reyes Católicos, por lo que tuvieron una intervención directa en la misma a través de la gestión del programa trazado directamente con el papa. Sin dejar de seguir las pautas canónicas, gozaron de un amplio margen de actuación, que aprovecharon para favorecer su visión del proyecto. El método empleado fue el envío de comisarios

\footnotetext{
52 Tenían voto en la oposición el prior carmelita de San Pablo de la Moraleja, el de San Andrés de Medina, el rector del colegio de la Compañía de Jesús también en dicha población, así como todos los licenciados y bachilleres universitarios de la villa en ambas especialidades, y podría votar en ambas oposiciones si alguno de ellos contaba con las dos. Las primeras cátedras fueron ocupadas por Antón Álvarez, una de artes, y por Alonso Fernández de Bobadilla, canónigo de la iglesia mayor de Medina, una de Teología (Ibídem, 163).

${ }^{53}$ Sobre las razones alegadas por Rubeo, véase Garrido, El hogar espiritual de Santa Teresa, 46.
} 
reales y pontificios a las casas de los religiosos con programas de reforma disciplinar, que se sustentaron sobre los procesos de autorreforma que se estaban poniendo en marcha en las distintas órdenes y que se plasmaron en las congregaciones de la Observancia. Se procuró implantar las medidas y mantener la unidad dentro de las distintas familias bajo un régimen de vida reformada ${ }^{54}$.

La mayoría de los religiosos vinculados a la reforma del Carmelo destacaron como predicadores, o bien, como comentadores de la Regla. Sin que fuesen excluyentes ambas actividades, la inclinación en el desempeño de su labor también se encontraba marcada por su formación y por su herencia en el ámbito de la espiritualidad. Fernando el Católico continuó la tradicional cercanía de los reyes aragoneses a la orden del Carmen y, como hemos señalado, su respaldo a Guillermo Tolzà fue esencial para que pudiese promover la reforma con eficacia. Para ello, Tolzá contó con el apoyo de su sólida formación como teólogo y jurista, sobre todo para escribir unos estatutos sobre la clausura y la vida común, que establecían severos castigos para los infractores ${ }^{55}$. Como vicario general, a partir de 1502, se ocupó de realizar la visita canónica a las provincias de España, siguiendo las directrices del rey y bajo la supervisión de Dom Mercader, a quien Fernando el Católico había encomendado la reforma de las órdenes mendicantes en la Corona de Aragón ${ }^{56}$. La cercanía de Mercader al rey se puso de manifiesto cuando fue designado para integrarse en el séquito que le acompañó a Nápoles en 1504 como confesor y consejero. No obstante, fue más relevante su nombramiento como presidente del Tribunal de la Inquisición General para toda la Corona de Aragón y Navarra, cargo que compartió con el dominico Juan Paul, sobre todo si consideramos la instrumentación del Santo Oficio por parte de los "fernandinos" como arma de revolución social en su actuación contra los judeoconversos vinculados a la facción "isabelina" 57 .

Por el contrario, como sucediese en otros ámbitos políticos y eclesiásticos,

\footnotetext{
54 García Oro, "Los carmelitas castellanos y la Monarquía en el Renacimiento”, 234-235.

55 Ibídem, 235-238; Velasco, Diccionario biográfico del Carmelo ibérico.

${ }^{56}$ Dom Luis Mercader Escolano fue hijo de los barones de Buñol. Inició sus estudios en su Valencia natal, pero se licenció en Artes y Teología en la Universidad de Salamanca, donde se doctoró en ambos Derechos y adquirió conocimientos avanzados de Matemáticas. Ingresó en la Cartuja de Valdecristo, donde destacó por sus dotes, de manera que el Capítulo General de 1489 le designó visitador de la provincia de Cataluña, y en 1494 fue designado para ocuparse en este cometido en tierras germanas. Su labor fue apreciada por Fernando el Católico, que se sirvió de él en varias embajadas ante el rey Ladislao de Hungría, el emperador Maximiliano I y ante el papa Alejandro VI, lo que le valió la estima de la Curia romana. Sobre su trayectoria, véase, Santiago Cantera Montenegro, OSB, "Los cartujos en la Península Ibérica en la Edad Media", en Del silencio de la Cartuja al fragor de la orden militar, coord. José Ángel García de Cortázar y Ramón Teja (Aguilar de Campoo: Fundación Santa María la Real, 2010), 54.

${ }^{57}$ Mercader escribió un libro sobre Las atribuciones puramente civiles del Tribunal de la Inquisición. Sobre la utilización política de la facción fernandina del tribunal de Inquisición, véase José Martínez Millán, "Las élites de poder durante el reinado de Carlos V a través de los miembros del Consejo de Inquisición (1516-1558)", Hispania 48 (1988): 103-168; Idem, "La herencia de Carlos V y la evolución política hispana", en La Corte de Carlos V , dir. José Martínez Millán (Madrid: Sociedad Estatal para la Conmemoración de los Centenarios de Felipe II y Carlos V, 2000), I, 45-140.
} 
Andalucía se convirtió en el destino de diversos partidarios de la reina Isabel, sobre todo, tras verse afectada su salud por las muertes de sus hijos y su alejamiento de las labores de gobierno. La erección de la provincia bética se debió, en gran medida, a la voluntad real, que apoyó las necesarias gestiones en Roma, así como al empuje de religiosos como Pedro Chaves, quien asumió la implantación de la reforma. Profesó en la Casa Grande sevillana en 1486. Considerado un gran orador, prestó sus servicios al Santo Oficio como calificador y dejó varios escritos destinados a rebatir la herejía. Algunos cronistas le pusieron en relación con Rodrigo Valer ${ }^{58}$. En este sentido, como hemos referido, a finales del siglo XV y mientras continuaba vinculada a Castilla, destacó un núcleo humanista en el convento de Sevilla relacionado con los estudios de la Biblia ${ }^{59}$. Valer tuvo conexión con los movimientos evangelistas, pero también con otros de inspiración más popular relacionados con el ámbito de las visiones proféticas o de la superstición ${ }^{60}$.

También desarrolló su labor en la provincia bética el P. Andrés Zaragoza, de origen abulense, como Alonso Suárez de Fuente el Sauce, que fue obispo de Mondoñedo y Lugo. En 1500, fue proveído en la diócesis de Jaén, y llevó consigo al P. Zaragoza como confesor, teólogo y consultor. También se debió al mismo la fundación del convento de carmelitas de Jaén. Sin duda, el prelado jienense era un hombre cercano a la reina Isabel la Católica, puesto que siendo obispo de Mondoñedo le proveyó Inquisidor General. Posteriormente, Felipe el Hermoso le nombró presidente del Consejo del Reino, y también ocupó el cargo de Comisario General de Cruzada. En las Constituciones salidas del sínodo diocesano celebrado en 1511, dio buena muestra de su seguimiento de la reforma promovida por Cisneros ${ }^{61}$.

Así mismo, Guillermo Tolzá y Luis Mercader, especialmente focalizado en la reforma de los conventos valencianos desde 1501, pudieron contar con la colaboración del P. Estaña, prior del convento de Valencia, y posteriormente provincial de Aragón y Valencia, y visitador de Portugal. Estuvo vinculado al convento de monjas de la Encarnación de Valencia desde su fundación. Este cenobio se convirtió en un excelente exponente de que elflorecimiento de la espiritualidad carmelitana observante, como consecuencia de las reformas promovidas por Audet y posteriormente por el general Rubeo, fue muy relevante, así como los frutos recogidos en el ámbito intelectual. Ambos aspectos merecieron el posterior elogio de Jerónimo Gracián ${ }^{62}$. Así mismo, durante el conflicto de las Germanías, el P. Estaña,

\footnotetext{
58 Velasco, Historia del Carmelo español, 254-255; Martínez Carretero, Los carmelitas en Sevilla, 101.

59 Sobre los carmelitas vinculados al mismo, véase Garrido, El solar carmelitano, 39.

60 Michel Boeglin, "Evangelismo y sensibilidad religiosa en la Sevilla del Quinientos: consideraciones acerca de la represión de los luteranos sevillanos", Studia historica. Historia Moderna 27 (2005): 163-189; Idem, "Valer, Camacho y los 'cautivos de la Inquisición'. Sevilla 1540-1541", Cuadernos de Historia Moderna 32 (2007): 113-134.

${ }_{61} \mathrm{Su}$ biografía aparece recogida en http://dbe.rah.es/biografias/22864/alonso-suarez-de-lafuente-del-sauce (consultado 14 de diciembre de 2020); Velasco, Historia del Carmelo español, 115-116.

62 Pablo María Garrido, "El carmelita Juan Sanz (1557-1608) promotor de la oración metódica y aspirativa”, Carmelus 17 (1970): 3-70; Jerónimo Gracián de la Madre de Dios, Obras. Editadas y anotadas por Silverio de Santa Teresa (Burgos: Tipografía de "El Monte Carmelo", 1933), III, 380382; Velasco, Historia del Carmelo español, 612-615.
} 
junto al dominico Gaspar Esteve, especialista en combatir el movimiento milenarista y al inquisidor Andrés Palacios entre otros mediadores, trataron de apaciguar los ánimos y facilitar la negociación, especialmente tras la entrada de Vicente Peris en Valencia el 2 de febrero de $1522^{63}$.

Este intento de contemporización y mediación fue realizado igualmente por otros religiosos en el conflicto de las Comunidades de Castilla, que se encontraban relacionados con la Universidad de Salamanca y con los herederos de las enseñanzas del teólogo Fernando de Roa, inscrito en la escolástica castellana, de la que había sido principal exponente Alonso de Madrigal ${ }^{64}$. La nueva perspectiva adoptada durante el siglo XV sobre el aristotelismo en la Universidad salmantina favoreció la aparición de estudios y escritos para la formulación de una serie de propuestas sobre la limitación del poder real, así como para proceder a una reforma de la Iglesia que, a la luz de la doctrina tomista, pretendía fomentar la formación del clero y se expresaba sobre un sustrato conciliarista. Este conciliarismo fue erradicado por los Reyes Católicos, por considerar que era nocivo para la autoridad papal. No obstante, este movimiento volvió a resurgir tras la muerte de Cisneros ${ }^{65}$. También conviene significar, entre los alumnos de Fernando de Roa, a Diego Ramírez de Villaescusa. Su posicionamiento en el conflicto comunero fue tratar de erigirse en una figura de mediación para alcanzar una solución pacífica y evitar males mayores al reino ${ }^{66}$. La vinculación con este grupo de los carmelitas castellanos relacionados con la reforma se establece a través del P. Miguel de Madrigal, emparentado con el Tostado. Nacido en Madrigal de las Altas Torres (Ávila), lo que sustenta su identificación con el ámbito isabelino, ingresó como carmelita en el convento de San Pablo de la Moraleja. Como hemos señalado, acudió como lector de Sentencias al Estudio general de Lérida, para después pasar a leer en Salamanca hasta conseguir el magisterio. En octubre de 1508,

${ }^{63}$ Ibídem, 199; Pablo Pérez García, "El dominico fray Gaspar Esteve (Barcelona, ¿1460?-Tremp ¿1530?) y la Germanía de Valencia", en Frailes, Santos y Devociones. Historias dominicanas en homenaje al P. Alfonso Esponera, ed. Emilio Callado Estela (Valencia: Tirant lo Blanch, 2020), 316-319.

${ }^{64}$ Jesús Luis Castillo Vegas, "La formación del pensamiento político comunero. De Fernando de Roa a Alonso de Castrillo", en Imperio y tiranía. La dimensión europea de las Comunidades de Castilla, ed. Istvan Szászdi León-Borja y María Jesús Galende Ruiz (Valladolid: Universidad de Valladolid, 2013), 83-110.

${ }^{65}$ José Joaquín Jerez, Pensamiento político y reforma institucional durante la guerra de la Comunidades de Castilla (1520-1521) (Madrid: Marcial Pons, 2007), 498-501.

${ }^{66}$ Miguel Jiménez Monteserín, "Don Diego Ramírez de Villaescusa y la prerreforma española”, en Diego Ramirez de Villaescusa: obispo y mecenas, coord. Juan Manuel Millán Martínez y Carlos Julián Martínez Soria (Cuenca: Ediciones de la Universidad de Castilla-La Mancha, 2009), 229-282; Alejandro Sáez Olivares, "Religión, política y cultura castellanas en torno a 1500. Diego Ramírez de Villaescusa y el cardenal Cisneros", Tiempos Modernos 35 (2017): 89; Félix Labrador Arroyo y Alejandro Sáez Olivares, "Diego Ramírez de Villaescusa y la revuelta de las Comunidades", en Las Comunidades de Castilla. Corte, poder y conflicto (1516-1525), dirs. Carlos Javier de Carlos Morales y Natalia González Heras (Madrid: Polifemo-UAM, 2020), 125-152. 
obtuvo el grado de maestro en Teología y se ocupó en la enseñanza, posiblemente, en la Universidad salmantina ${ }^{67}$.

La cercanía de Carlos $\mathrm{V}$ a la orden del Carmen quedó plasmada en su relación con varios religiosos. En este sentido, destacaron el prior del convento de Zaragoza Pedro Ribas y el prior de San Andrés Hernando del Barco, puesto que ambos confesaron en alguna ocasión al emperador. El primero de ellos logró que sufragase diversas obras en varios conventos, como el de Zaragoza y el de Bruselas, le acompañó en diversos viajes y pasó mucho tiempo en Flandes, donde falleció en $1577^{68}$. En el caso de Hernando del Barco, perteneciente a la familia de los marqueses de Campollano, promovido a obispo de Salona en 1521 con retención del priorato de San Andrés, logró, como hemos referido, interesar a Carlos V por la fundación de un convento en Valladolid ${ }^{69}$. Sin embargo, el tiempo de las Comunidades y la derrota de Villalar trajo, entre otras consecuencias, el aumento de frailes que vagaban por los caminos, fugados de los conventos e integrando la resistencia a someterse a la reforma y al rigor de la observancia. Como otros institutos, los carmelitas tomaron la determinación de encargarse de su propia reforma y no descuidar la formación de los frailes. En este contexto fue elegido Nicolas Audet prior general en 1524, por lo que su propuesta de reforma fue acogida y puesta en práctica ${ }^{70}$. Si bien su intento fue apoyado por el papa Clemente VII y también por el emperador Carlos $\mathrm{V}$, las consecuencias políticas y en el ámbito de la espiritualidad del "Saco de Roma" de 1527 afectaron a algunas decisiones sobre la misma. Desde esta perspectiva, no parece baladí el intento de confiar la implantación de la reforma de las provincias peninsulares al luso Baltasar Limpo. También se inserta en este contexto la resistencia de Hernando del Barco a abandonar el priorato del colegio de San Andrés y su recurso al Consejo Real ${ }^{71}$.

Por otra parte, la expansión de las ideas luteranas provocó que se incrementasen los recelos antihumanistas y, tras el Saco, se intensificaron los discursos antierasmistas. En 1524 fue nombrado Inquisidor General el arzobispo de Sevilla Alonso de Manrique, que se encontraba identificado con la reforma de Cisneros y su florecimiento en la Universidad de Alcalá de Henares, y brindó su

${ }^{67} \mathrm{Si}$ bien los cronistas e historiadores de la orden elogian de manera profusa su formación y saber, ninguno de ellos refiere que escribiese ninguna obra (Garrido, El hogar espiritual de Santa Teresa, 49; Llamas Martínez, "Carmelitas españoles pretridentinos", 388-389).

${ }^{68}$ Escribió De praedestinatorum exiguo numero; De via ad coelum ardua; De juvamine animabus in Purgatorio existentibus promovendo (ms. desaparecidos). Véase Feliz Latassa y Ortín, Biblioteca nueva de los Escritores Aragoneses que florecieron desde el año de 1500 hasta 1599 (Pamplona: Oficina de Joaquín de Domingo, 1798), I, 341-342; López Melús, Carmelitas que dejaron buella, 39; Velasco, Diccionario biográfico del Carmelo ibérico.

${ }^{69}$ Dejó escrito un Comentario al Viejo y Nuevo Testamento en la biblioteca del colegio de San Andrés para aprovechamiento de los estudiantes (Garrido, El hogar espiritual de Santa Teresa, 54-55; Velasco, Historia del Carmelo español, 257-258; Llamas Martínez, “Carmelitas españoles pretridentinos”, 386-387).

${ }^{70}$ Esta misma intención tuvieron otras órdenes, como los franciscanos conventuales de la provincia de Santiago, que expresaron esta determinación en 1524, aunque no tuvo aplicación en los decenios siguientes (Melquíades Andrés Martín, "Reforma y estudios de Teología", 43-84).

${ }^{71}$ Velasco, El Colegio Mayor Universitario, 39-40. 
protección a Juan de Ávila. Manrique prestó su apoyo a la vía del recogimiento, compartió los planteamientos erasmistas y favoreció el conocimiento de los escritos de Erasmo. Los sucesos acaecidos en Roma provocaron que los teólogos conservadores arreciasen en sus acusaciones hacia dicho humanista, a quien culpaban de causar perjuicio a la Iglesia y compartir las tesis luteranas. Ante esta situación, Manrique hubo de convocar la célebre congregación de Valladolid de 1527 para tratar esta problemática. A pesar del fracaso de los detractores de Erasmo en dicha reunión, la caída en desgracia de Manrique y la muerte de Mercuriano de Gattinara dejó al erasmismo sin defensores en el entorno cortesano ${ }^{72}$. Como hemos referido, cuando el arzobispo de Sevilla fue a residir a su sede arzobispal, le acompañó el Maestro Juan Quirós, teólogo, consejero y hombre de confianza, a quien quiso poner al frente de la reforma de los carmelitas en Andalucía a través de alcanzar su elección como provincial en 1533, si bien se ocupó por un breve periodo en esta labor. Formado, posiblemente, en la Universidad de Alcalá de Henares, su identificación con los planteamientos defendidos por Manrique supuso la pervivencia de la corriente erasmista en la provincia bética. Dejó escritas dos obras enmarcadas en la temática del humanismo cristiano, De ratione civilis status liber I y Lectiones solemnes de regimine principum libri II, cuyo rastro se pierde a comienzos del siglo XVII y que se dan por desaparecidas ${ }^{73}$.

Efectivamente, los enviados de Audet llegaron en 1530 para proceder a implantar la reforma con resultados desiguales, y su actuación vino a coincidir con un cambio en el ámbito ideológico que se manifestó, entre otras cuestiones, en que las obras de Erasmo fueron prohibidas en un incesante goteo desde principios de 1536, sin que nunca pesase una condena global sobre el autor. Así mismo, la Inquisición comenzó a procesar a los erasmistas bajo la acusación de ser alumbrados o luteranos. Esta evolución se reflejó también en los órganos de gobierno de la Inquisición. El "partido castellano" no sólo estaba compuesto por los descendientes políticos del "partido fernandino", sino que también heredaron sus valores religiosos. En consecuencia, utilizaron la Inquisición no sólo como instrumento de exclusión social, sino también como órgano idóneo para imponer una ideología. Así, Juan Pardo de Tavera, sobrino de Diego Deza, fue designado Inquisidor General en 1539, cargo que ocupó hasta su fallecimiento en 1545, y a quien Carlos $\mathrm{V}$ encomendó el seguimiento de los procesos de reforma de las órdenes religiosas ${ }^{74}$.

No obstante, el apoyo de Carlos $\mathrm{V}$ al programa de reformas promovido por Audet se dejó notar en diversas actuaciones, entre las que podemos destacar la carta dirigida al papa Clemente VII en 1532, altamente elogiosa para la gestión del prior

\footnotetext{
72 Miguel Avilés Fernández, "El Santo Oficio en la primera etapa carolina”, Historia de la Inquisición en España y América, dirs. Joaquín Pérez Villanueva y Bartolomé Escandell Bonet (Madrid: BAC, 1984), I, 448-472. Sobre la dimensión política de estas cuestiones, véase Manuel Rivero Rodríguez, Gattinara, Carlos V y el sueño del Imperio (Madrid: Silex, 2005).

${ }^{73}$ Velasco, Historia del Carmelo español, 253, 280; Rodríguez Carretero, Epytome historial de los carmelitas, 96; Pablo María Garrido, "El testamento de don Alonso Manrique, arzobispo de Sevilla, en 1525”, en Homenaje a Pedro Sainz Rodríguez: Tomo I: Repertorios, textos y comentarios (Madrid: FUE, 1986), 262-264.

${ }^{74}$ Andrés Martín, "La espiritualidad española”, 169-177; La Corte de Carlos V, III, 316-325.
} 
general, y en apoyo de la ampliación de la iglesia de Santa María Transpontina en Roma $^{75}$. Ciertamente, la reforma del Carmelo siguió su curso, puesto que, en torno a 1546-1547, el nuevo Vicario General Damián de León, provincial de Aragón y sucesor de Pedro Bou en el cargo, procedió a realizar una nueva visita, a la que siguió una posterior en 1552. En el caso de Andalucía, la persistencia de las divisiones en el seno de la provincia había provocado que no se hubiese terminado de introducir la reforma, por lo que el Vicario General Damián de León siguió la directriz de los primigenios visitadores de Audet, encomendando la Bética al exprovincial de Castilla Gregorio Fernández cuando finalizó su sexenio en dicho cargo, que ocupó entre 1550 y $1556^{76}$.

Así pues, la orden del Carmen se aproximaba a mediar la centuria con tres escenarios en el ámbito de la espiritualidad. Mientras que Cataluña y Aragón, en la inercia de su legado medieval y con el tradicional patrocinio de los reyes aragoneses se habían encajado en los presupuestos "fernandinos", Andalucía vivía una división entre aquellos que se formaban en el Colegio de Santo Tomás, inscrito en el tomismo, y aquellos que recibieron una educación alcalaína, humanista y erasmista. En el caso de Castilla, la espiritualidad carmelitana estuvo influenciada por el magisterio de la universidad de Salamanca y la renovación de la escolástica promovida por Francisco de Vitoria. Esta cuestión es esencial para explicar que Rengifo buscase su modelo en el colegio dominico de San Gregorio de Valladolid, e igualmente nos va a proporcionar algunas claves que contribuyen a explicar el fracaso del proyecto además de las expuestas.

Sin pretender realizar una comparación de los proyectos colegiales de Baltasar Limpo y de Diego Rengifo conviene señalar algunas diferencias esenciales a pesar de que se desarrollaron de forma paralela. Ambos contaron con el apoyo papal y con el respaldo del prior general. En el caso de Limpo, el patronazgo del rey luso y su propia capacidad económica a través de las dignidades que ostentó sirvieron para sustentar un proyecto, que se inscribió desde sus cimientos en las directrices tridentinas, puesto que Limpo acudió a la asamblea conciliar. Evidentemente, la fundación del colegio de Santa Ana partió de una situación menos sólida por la paupérrima situación de la provincia, las limitadas fuerzas del fundador, y con un apoyo económico testimonial por parte de Carlos $\mathrm{V}$, quien, cuando el proyecto se estaba consolidado, se encontraba al final de su reinado. No obstante, la cercanía de Rengifo con el emperador y su situación en Corte debía ser significativa, puesto que Nicolás Audet le nombró procurador de las cuatro provincias carmelitas españolas ante la Curia Real en 1555. Sin embargo, el Colegio de Medina del Campo se fundó en el mismo año que Carlos $\mathrm{V}$ hizo parada en dicha población en su camino hacia Yuste $^{77}$.

\footnotetext{
${ }^{75}$ José María de Garganta, "El papa Clemente VII y sus criterios jurídicos en la reforma de las órdenes mendicantes", AHDE 23 (1953): 312.

${ }^{76}$ Garrido, El solar carmelitano, 49-50.

${ }^{77}$ Los diversos estudios reflejan la cercanía con el emperador, a quien debió confesar en algunas ocasiones (Velasco, San Juan de la Cruz, 153 ss.).
} 
De la misma manera y, a pesar de que no se conservan los estatutos del colegio establecidos en 1548, los estudios que nos acercan al conocimiento del contenido de los mismos no hacen referencia una cuestión que parece prioritaria en el proyecto de Limpo como era la exigencia a los colegiales de la limpieza de sangre. Ciertamente, el fundador del Colegio de San Gregorio de Valladolid, Alonso de Burgos, se había declarado contrario a la introducción de ninguna discriminación para la admisión de alumnos por esta cuestión ${ }^{78}$. El celo en la orden de Santo Domingo se desarrolló con posterioridad, impulsado por los sectores más rigoristas, y su puesta en práctica tuvo que enfrentarse a una importante resistencia. Las consecuencias de la revuelta comunera y la asunción de la dirección de la reforma por parte de García de Loaysa pusieron las bases para la adopción de esta reglamentación, que, en el caso del Colegio de San Gregorio, se realizó en 1538. El falaz argumento esgrimido para obtener el beneplácito del papa Paulo III fue que los descendientes de judíos eran más propensos a caer en la herejía. Realmente, la pretensión también era acabar con cualquier vestigio dentro de la orden de disidencia a las directrices marcadas por el sector más intransigente, especialmente con aquellos que seguían la estela del humanismo cristiano ${ }^{79}$.

Ciertamente, la pérdida documental nos impide poder afirmar qué opción tomó Rengifo respecto a la discriminación de los candidatos para estudiar en Santa Ana en relación con la limpieza de sangre, pero este requerimiento no estaba contemplado en las Constituciones de la orden del Carmen, ni se hizo presente o se despertó una polémica en su seno en relación con esta cuestión hasta más avanzada la centuria en el contexto de la visita del General Rubeo ${ }^{80}$. Evidentemente, la vía de espiritualidad referencia para Rengifo la encontramos en su labor como rector del colegio de San Andrés, que, como hemos referido, se encontraba vinculado al magisterio de Francisco de Vitoria, desde los años en que Hernando del Barco estaba al frente del mismo. Del mismo modo, fallecido Vitoria en 1546, Rengifo estableció que se siguiesen las enseñanzas en Filosofía del dominico Domingo de Soto, discípulo de Vitoria, formado en la Universidad de Alcalá de Henares, donde recibió las enseñanzas de Tomás de Villanueva, y en París. Tras ocuparse de confesar a Carlos V por un corto periodo (1548-1550), Domingo de Soto retornó a Salamanca, donde pudo comprobar el incremento de los recelos ante el avance del protestantismo. La Inquisición se había puesto bajo el mandato de Fernando de Valdés en 1547, que realizó unos cambios en el Santo Oficio que preparaban a la

\footnotetext{
${ }^{78}$ Jorge Díaz Ibáñez, “Alonso de Burgos y la fundación y primeros estatutos del colegio de San Gregorio de Valladolid. La regulación de la vida religiosa y académica de los dominicos observantes en la Castilla del siglo XV", Cuadernos de Historia del Derecho 23 (2016): 61-63.

${ }^{79}$ Guillermo Nieva Ocampo, "La observancia dominica y la Monarquía castellana: Compromiso político y disciplinamiento social", en La Corte en Europa: política y religión (siglo XVI-XVIII), coord. José Martínez Millán, Manuel Rivero Rodríguez, Gijs Versteegen (Madrid: Polifemo, 2012), I, 513-562; Idem, "Frailes revoltosos: corrección y disciplinamiento social de los dominicos de Castilla en la primera mitad del siglo XVI", Hispania 71 (2011): 39-42; Rafael M. Pérez García, "Dominicos, conversos y limpieza de sangre en España. Siglos XV-XVI", eHumanista/Conversos 5 (2017), 171-180.

${ }^{80}$ Steggink, La reforma del carmelo español, 183.
} 
institución para el proceso de confesionalización de la Monarquía desarrollado durante el reinado de Felipe II, así como para los derivados de la celebración de la tercera etapa del Concilio de Trento ${ }^{81}$. También sufrió los efectos negativos del cambio producido el mayor benefactor del colegio-convento en Medina del Campo, Rodrigo de Dueñas, cuya condición de judeoconverso provocó su salida del Consejo de Hacienda en $1555^{82}$. En este sentido, el oscurantismo sobre los orígenes de Rengifo podría apuntar a esta misma causa.

Las fracturas y divisiones dentro de las órdenes religiosas siguieron sin cerrarse, como se puso de manifiesto en el proceso inquisitorial que se instruyó contra el arzobispo de Toledo Bartolomé de Carranza, así como en las sospechas contra el humanismo vinculado a los estudios bíblicos, que se concretó, entre otras manifestaciones, en los procesamientos de los hebraístas de la Universidad de Salamanca. En este sentido, el P. Martín García, que ocupó una de las cátedras de Teología en Santa Ana y acudió a solicitar al Capítulo General reunido en Piacenza en 1575 que se forzase a los regidores de Medina del Campo a cumplir con su compromiso, era un reputado biblista formado en la Universidad de Salamanca, donde, además de seguir la citada estela, recibió las enseñanzas en hebreo y caldeo del judeoconverso Alonso de Montemayor ${ }^{83}$. Ante el mismo Capítulo solicitó que se cumpliese con la voluntad de Rengifo y que la dotación económica pasase al colegio de San Andrés, cuestión que fue finalmente sancionada por el General Rubeo. Ciertamente, el proyecto de Rengifo no encajaba completamente en los planteamientos imperantes en la Corte ni con las directrices tridentinas.

Así pues, la reforma del Carmelo fue tardía respecto a la aplicación en otras órdenes religiosas, pero también fue madura y eficaz. La implantación en Castilla, epicentro de la observancia y de su proyecto educativo, trajo la resistencia a los cambios y la pérdida de componentes en una exigua grey. Las estrecheces económicas agravaron las limitaciones de la pequeña cantera existente, y también condicionaron que los esfuerzos realizados en los decenios anteriores a la celebración del Concilio de Trento diesen frutos menos vistosos. No obstante, estos logros sustentaron un renovado ideal carmelitano que tuvo un destacado posicionamiento en el ámbito de la espiritualidad. La falta de institucionalización de la reforma con la conformación de una rama observante al estilo de otras órdenes religiosas posibilitó

${ }^{81}$ José Luis González Novalín, El Inquisidor General Fernando de Valdés (Oviedo: Universidad de Oviedo, 1968); José Martínez Millán, "En busca de la ortodoxia: el Inquisidor General Diego de Espinosa”, en La Corte de Felipe II, dir. José Martínez Millán (Madrid: Alianza 1994), 189-228; Ignacio Fernández Terricabras, "El fin de las terceras vías. El concilio de Trento y la definición de la frontera confesional”, en Identidades y fronteras culturales en el mundo ibérico de la Edad Moderna, eds. José Luis Betrán, Bernat Hernández y Doris Moreno (Barcelona: Universidad de Barcelona, 2016), 145-165.

${ }^{82}$ José Martínez Millán y Carlos Javier de Carlos Morales, “Conversos y élites de poder en Castilla durante la primera mitad del siglo XVI: Rodrigo de Dueñas, consejero de Hacienda de Carlos V”, en Las tres culturas en la Corona de Castilla y los Sefardies (Salamanca: Junta de Castilla y León, 1990), 149-164.

${ }^{83}$ Beltrán de Heredia, Las corrientes de espiritualidad, 110 ss; Roberto López Vela, "El arzobispo de Toledo Bartolomé de Carranza y la 'reforma' de la iglesia”, Tiempos Modernos 9 (2018): 451-482; el P. Martín García dejó una obra manuscrita titulada De similitudinibus Sacrae Scriptura. En torno a su figura, véase Velasco, San Juan de la Cruz, 166, 174, 238, 311 ss. 
que el Carmelo siguiera apareciendo como "orden no reformada", lo que definió el tratamiento recibido por el papa y los monarcas en el periodo postridentino y sirvió de impulso al movimiento descalzo. Sin embargo, conviene insistir en que no se puede explicar el impulso renovador teresiano apoyándose en el denigrado estado de la provincia de Castilla, puesto que, como hemos señalado, su reforma fue proclamada por la brevis instructio sobre el estado de las provincias de la Orden al mediar el siglo XVI. 


\section{REFERENCIAS BIBLIOGRÁFICAS}

Álvarez, Francisco, "El movimiento bíblico en Sevilla durante el siglo XVI”, Archivo bispalense 26 (1957): 9-46.

Andrés Martín, Melquíades, "La espiritualidad española en tiempos de Carlos V”, en Carlos $V$ y la quiebra del humanismo político en Europa (1530-1558), coord. José Martínez Millán, 4 vols. (Madrid: Sociedad Estatal para los Centenarios de Felipe II y Carlos V, 2001), IV, 157-180.

—, "Reforma y estudio de Teología en los franciscanos españoles", Anthologica Annua 8 (1961): 43-84.

- "Corrientes culturales en tiempos de los Reyes Católicos y recepción de Erasmo", en El erasmismo en España, eds. Manuel Revuelta Sañudo y Ciriaco Morón Arroyo (Santander: Sociedad Menéndez Pelayo, 1986), 73-95.

Antolín, Fortunato, OCD, "Notas sobre el padre Rubeo y la congregación mantuana", Revista Monte Carmelo 101,1 (1993): 69-83.

Aurea [et] saluberrima ordinis Fratrum Deiparae virginis Mariae de mo[n]te Carmelo Statuta in Capitulo G[e]n[er]ali Venetiis celebrato... ad instaurationem eiusdem ordinis, p[ro]pie simul \& sapienter ordinata; Isagogicon preciosissimis comparandu[m] ge [r]mis ad reformationem vitae regularis \& Sanctimoniae patrum Carmeli montis; Constitutiones ordinatae per R. Magistru[m] Io. Soret Generalem, approbatae \& publicatae per diffinitores Capituli Generalis Bruxelle[n] sis celebrati Anno D[omi]ni M.CCCC.LXVI. et correctae ac emendatae per R. Magistrum Nicolaum Audet ordinis Priorem Generalem \& diffinitores Capituli Generalis celebrati Venetiis. Anno Domini M.D.XXIIII (Venetiis: Coimpressae per Ioannem Antoniu[m] \& Fratres de Sabio...., 1524).

Avilés Fernández, Miguel, "El Santo Oficio en la primera etapa carolina", en Historia de la Inquisición en España y América, dirs. Joaquín Pérez Villanueva y Bartolomé Escandell Bonet, 3 vols. (Madrid: BAC, 1984), I, 448-472.

Beltrán de Heredia, Vicente, Las corrientes de espiritualidad entre los dominicos de Castilla durante la primera mitad del siglo XVI (Salamanca: Biblioteca de Teólogos Españoles, 1941).

Boeglin, Michel, "Evangelismo y sensibilidad religiosa en la Sevilla del Quinientos: consideraciones acerca de la represión de los luteranos sevillanos", Studia Historica. Historia Moderna 27 (2005): 163-189.

—, "Valer, Camacho y los 'cautivos de la Inquisición'. Sevilla 1540-1541”, Cuadernos de Historia Moderna 32 (2007): 113-134. 
Cantera Montenegro, Santiago, OSB, "Los cartujos en la Península Ibérica en la Edad Media", en Del silencio de la Cartuja al fragor de la orden militar, coord. José Ángel García de Cortázar y Ramón Teja (Aguilar de Campoo: Fundación Santa María la Real, 2010), 33-60.

Castillo Vegas, Jesús Luis, "La formación del pensamiento político comunero. De Fernando de Roa a Alonso de Castrillo", en Imperio y tiranía. La dimensión europea de las Comunidades de Castilla, ed. Istvan Szászdi León-Borja y María Jesús Galende Ruiz (Valladolid: Universidad de Valladolid, 2013), 83-110.

Díaz Ibáñez, Jorge, "Alonso de Burgos y la fundación y primeros estatutos del colegio de San Gregorio de Valladolid. La regulación de la vida religiosa y académica de los dominicos observantes en la Castilla del siglo XV', Cuadernos de Historia del Derecho 23 (2016): 41-100.

Fernández Terricabras, Ignacio, "El fin de las terceras vías. El concilio de Trento y la definición de la frontera confesional", en Identidades y fronteras culturales en el mundo ibérico de la Edad Moderna, eds. José Luis Betrán, Bernat Hernández y Doris Moreno (Barcelona: Universidad de Barcelona, 2016), 145-165.

García Oro, José, La reforma de los religiosos españoles en tiempos de los Reyes Católicos (Valladolid: Instituto Isabel La Católica de Historia Eclesiástica, 1969).

- "La reforma del Carmelo castellano en la etapa pretridentina", Carmelus 29 (1982): 130-148.

—, "Los carmelitas castellanos y la Monarquía en el Renacimiento. Proyectos religiosos y protagonismos personales", en In labore requies (Homenaje de la Región Ibérica Carmelita a los Padres Pablo Garrido y Balbino Velasco), ed. Fernando Millán Romeral (Roma: Edizioni Carmelitane, 2007), 229-258.

Garganta, José María de, "El papa Clemente VII y sus criterios jurídicos en la reforma de las órdenes mendicantes", AHDE 23 (1953): 289-328.

Garrido, Pablo María, El hogar espiritual de Santa Teresa. En torno al estudio del Carmelo español en tiempos de la Santa (Roma: Institutum Carmelitanum, 1983).

—, El solar carmelitano de San Juan de la Cruz. La antigua provincia de Castilla (1416-1836) (Madrid: BAC, 1996).

-, "El carmelita Juan Sanz (1557-1608) promotor de la oración metódica y aspirativa", Carmelus 17 (1970): 3-70. 
—, "El testamento de don Alonso Manrique, arzobispo de Sevilla, en 1525", en Homenaje a Pedro Sáinz Rodríguez. Tomo I: Repertorios, textos y comentarios (Madrid: FUE, 1986), 261-282.

González Novalín, José Luis, El Inquisidor General Fernando de Valdés (Oviedo: Universidad de Oviedo, 1968).

Gracián de la Madre de Dios, Jerónimo, Obras. Editadas y anotadas por Silverio de Santa Teresa (Burgos: Tipografía de "El Monte Carmelo", 1933).

Grosso, Giovanni, Il B. Jean Soreth (1394-1471), Priore generale, riformatore e maestro spirituale dell'Ordine Carmelitano (Roma: Textus et Studia Historica Carmelitana, 2007).

—, "Tra fedeltà e reforma. Cultura e libri nei conventi dei Carmelitani del XVI secolo", en Libri e biblioteche: le letture dei frati mendicanti tra Rinascimento ed età moderna (Spoleto: Centro Italiano di Studi sull'Alto Medioevo, 2019), 223-249.

Jerez, José Joaquín, Pensamiento político y reforma institucional durante la guerra de las Comunidades de Castilla (1520-1521) (Madrid: Marcial Pons, 2007).

Jiménez Monteserín, Miguel, "Don Diego Ramírez de Villaescusa y la prerreforma española”, en Diego Ramírez de Villaescusa: obispo y mecenas, coord. Juan Manuel Millán Martínez y Carlos Julián Martínez Soria (Cuenca: Ediciones de la Universidad de Castilla-La Mancha, 2009), 229-282.

Labrador Arroyo, Félix y Sáez Olivares, Alejandro, "Diego Ramírez de Villaescusa y la revuelta de las Comunidades", en Las Comunidades de Castilla. Corte, poder y conflicto (1516-1525), dirs. Carlos Javier de Carlos Morales y Natalia González Heras (Madrid: Polifemo-UAM, 2020), 125-152.

Lasarte López, José Antonio y Royo García, Ramón, Visita pastoral de la diócesis de Zaragoza. Años 1536-1537 (Zaragoza: Institución Fernando el Católico, 2020).

Latassa y Ortín, Félix, Biblioteca nueva de los Escritores Aragoneses que florecieron desde el año de 1500 hasta 1599 (Pamplona: Oficina de Joaquín de Domingo, 1798).

López, Anastasio, OFM, "Confesores de la familia real de Castilla", Archivo Iberoamericano 31 (1929): 5-75.

López Melús, Rafael María, Carmelitas que dejaron buella (Onda: AMACAR, 2003).

López Vela, Roberto, "El arzobispo de Toledo Bartolomé de Carranza y la 'reforma' de la iglesia", Tiempos Modernos 9 (2018): 451-482. 
Llamas Martínez, Enrique, "Carmelitas españoles pretridentinos", en Repertorio de las Ciencias Eclesiásticas en España, 3. Siglos XIII-XVI (Salamanca: Instituto de Historia de la Teología Española, 1971).

Martínez Carretero, Ismael, Los carmelitas en Sevilla. 650 años de presencia (1358-2008) (Sevilla: Ediciones Provincia Bética, 2009).

Martínez Cuesta, Ángel, "El movimiento recoleto en los siglos XVI y XVII", Recollectio 5 (1982): 5-47.

—, Agustinos Recoletos. Historia y espiritualidad (Madrid: AGVSTINVS, 2007).

Martínez Millán, José, "Las élites de poder durante el reinado de Carlos V a través de los miembros del Consejo de Inquisición (1516-1558)", Hispania 48 (1988): 103-168.

- "La herencia de Carlos V y la evolución política hispana", en La Corte de Carlos V, dir. José Martínez Millán (Madrid: Sociedad Estatal para la Conmemoración de los Centenarios de Felipe II y Carlos V, 2000), I, 45-140.

—, "En busca de la ortodoxia: el Inquisidor General Diego de Espinosa", en La Corte de Felipe II, dir. José Martínez Millán (Madrid: Alianza 1994), 189-228.

Martínez Millán, José y Carlos Morales, Carlos Javier de, dirs., Felipe II (1527-1598). La configuración de la monarquía hispana (Valladolid: Junta de Castilla y León, 1998).

—, "Conversos y élites de poder en Castilla durante la primera mitad del siglo XVI: Rodrigo de Dueñas, consejero de Hacienda de Carlos V", en Las tres culturas en la Corona de Castilla y los sefardíes (Salamanca: Junta de Castilla y León, 1990), 149-164.

Meseguer Fernández, Juan, "Franciscanismo de Isabel la Católica", Archivo Iberoamericano 19 (1959): 153-195.

Muñoz Delgado, Vicente, "Nominalismo, lógica y humanismo", en El erasmismo en España, eds. Manuel Revuelta Sañudo y Ciriaco Morón Arroyo (Santander: Sociedad Menéndez Pelayo, 1986), 109-174.

Nieva Ocampo, Guillermo, "La observancia dominica y la Monarquía castellana: Compromiso político y disciplinamiento social", en La Corte en Europa: Política y Religión (siglo XVI-XVIII), coords. José Martínez Millán, Manuel Rivero Rodríguez y Gijs Versteegen (Madrid: Polifemo, 2012), I, 513-562. 
-, "Frailes revoltosos: corrección y disciplinamiento social de los dominicos de Castilla en la primera mitad del siglo XVI", Hispania 71 (2011): 39-64.

Pérez, Joseph, "El erasmismo y las corrientes espirituales afines", en El erasmismo en España, eds. Manuel Revuelta Sañudo y Ciriaco Morón Arroyo (Santander: Sociedad Menéndez Pelayo, 1986), 323-338.

Pérez García, Pablo, "El dominico fray Gaspar Esteve (Barcelona, ¿1460?-Tremp, ¿1530?) y la Germanía de Valencia", en Frailes, Santos y Devociones. Historias dominicanas en homenaje al P. Alfonso Esponera, ed. Emilio Callado Estela (Valencia: Tirant lo Blanch, 2020), 299-330.

Pérez García, Rafael M., "Dominicos, conversos y limpieza de sangre en España. Siglos XV-XVI", eHumanista/ Conversos 5 (2017): 167-191.

Rivero Rodríguez, Manuel, Gattinara. Carlos $V$ y el sueño del Imperio (Madrid: Sílex, 2005).

Rodríguez Carretero, Miguel, Epytome historial de los carmelitas de Andalucía y Murcia (Sevilla: Ediciones Provincia Bética, 2000).

Sáez Olivares, Alejandro, "Religión, política y cultura castellanas en torno a 1500. Diego Ramírez de Villaescusa y el cardenal Cisneros", Tiempos Modernos 35 (2017): 85-117.

Staring, Adrianus, Der Karmelitengeneral Nikolaus Audet und die katholische Reform des XVT.Jabrhunderts. Textus et studia histórica Carmelitana vol. 3. (Roma: Institutum Carmelitanum, 1959).

Steggink, Otger, La reforma del carmelo español. La visita canónica del general Rubeo y su encuentro con Santa Teresa (1566-1567) (Ávila: Diputación Provincial de ÁvilaInstitución Gran Duque de Alba, 1993).

Velasco Bayón, Balbino, San Juan de la Cru\%. A las raices del hombre y del carmelita (Madrid: Editorial de Espiritualidad, 2009).

—, Historia del Carmelo español (Roma: Institutum Carmelitarum, 1990).

—, "Documentos del siglo XIII sobre los carmelitas de España", Carmelus 33 (1986): 109-123.

—, Diccionario biográfico del Carmelo ibérico (Roma: Edizioni Carmelitane, 2019). 
—, "El convento de Carmelitas de Huesca", Carmelus 26 (1979): 137-157.

—, "El convento de carmelitas calzados de Toledo", Anales Toledanos 17 (1983): 2954.

—, El Colegio Mayor Universitario de carmelitas de Salamanca (Madrid: CSIC, 1978).

—, História da Ordem do Carmo em Portugal (Lisboa: Paulinas, 2001).

-, San Juan de la Cruz. A las raíces del hombre y del carmelita (Madrid: Editorial de Espiritualidad, 2009).

Wermers, Manuel Maria, "Os primeiros estatutos do colegio universitário carmelita de Coimbra”, Carmelus 9 (1962): 96-125.

Recibido: 27 de enero de 2021

Aprobado: 5 de marzo de 2021 